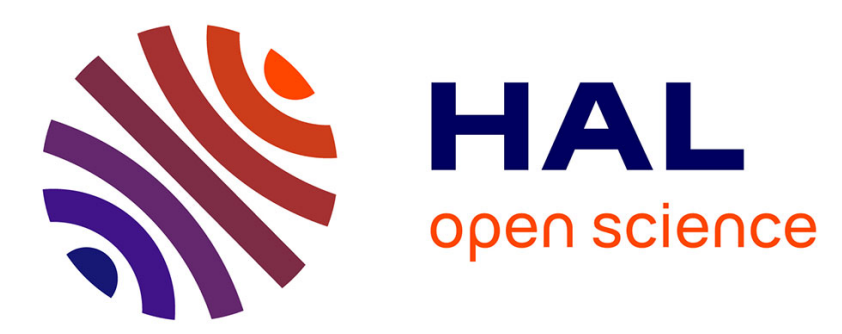

\title{
Regionalizing Rainfall at Very High Resolution over La Réunion Island: A Case Study for Tropical Cyclone Ando
}

Benjamin Pohl, Béatrice Morel, Christelle Barthe, Olivier Bousquet

\section{- To cite this version:}

Benjamin Pohl, Béatrice Morel, Christelle Barthe, Olivier Bousquet. Regionalizing Rainfall at Very High Resolution over La Réunion Island: A Case Study for Tropical Cyclone Ando. Monthly Weather Review, 2016, 144 (11), pp.4081-4099. 10.1175/MWR-D-15-0404.1 . hal-01378373

\section{HAL Id: hal-01378373 \\ https://hal.science/hal-01378373}

Submitted on 18 Oct 2016

HAL is a multi-disciplinary open access archive for the deposit and dissemination of scientific research documents, whether they are published or not. The documents may come from teaching and research institutions in France or abroad, or from public or private research centers.
L'archive ouverte pluridisciplinaire HAL, est destinée au dépôt et à la diffusion de documents scientifiques de niveau recherche, publiés ou non, émanant des établissements d'enseignement et de recherche français ou étrangers, des laboratoires publics ou privés. 


\title{
Regionalizing Rainfall at Very High Resolution over La Réunion Island: A Case Study for Tropical Cyclone Ando
}

\author{
BENJAMIN POHL \\ CRC/Biogéosciences, UMR6282, CNRS/Université de Bourgogne Franche-Comté, Dijon, France \\ BÉATRICE MOREL \\ LE2P, Université de La Réunion, St-Denis, La Réunion, France \\ Christelle BARTHE AND Olivier BOUSQuet \\ Laboratoire de l'Atmosphère et des Cyclones, UMR8105, CNRS/Université de La Réunion/Météo-France, \\ St-Denis, La Réunion, France
}

(Manuscript received 20 November 2015, in final form 30 June 2016)

\begin{abstract}
Ensemble simulations of Tropical Cyclone (TC) Ando (31 December 2000-9 January 2001) are performed over the southwest Indian Ocean using the nonhydrostatic WRF Model. Nested domains centered over the island of La Réunion allow for the simulation of local rainfall amounts associated with TC Ando at very high resolution (680-m grid spacing). The model is forced by and nudged toward ERA-Interim during the first (1-6) day(s) of the TC's life cycle. The nudging ends at various dates to constrain either the whole life cycle or only parts of it.

As expected, results show weakened member dispersion, as the relaxation lasts longer, with more members producing similar cyclone tracks and intensities. The model shows reasonable skill to simulate local rainfall amounts and distribution, as soon as the simulated TC approaches La Réunion with a realistic distance and azimuth. Strong lower-level wind associated with the TC is forced to ascend over the slopes of the island. The model is able to successfully simulate the extreme daily precipitation amounts $(>1200 \mathrm{~mm})$ and their distribution over the highest parts of La Réunion. Nevertheless, smaller-scale features of the rainfall field are less realistic in the simulations. The wind speed and direction upstream of the island are the main drivers of such local uncertainties and errors, and they appear as an important issue to assess the local impacts of the TC over such a complex terrain.
\end{abstract}

\section{Introduction}

La Réunion $\left(21^{\circ} \mathrm{S}, 55^{\circ} \mathrm{E}\right)$ is a small mountainous island $\left(2512 \mathrm{~km}^{2}\right)$ in the southwest Indian Ocean (SWIO), located $\sim 800 \mathrm{~km}$ off the eastern coast of Madagascar (Fig. 1a). It is composed of two volcanoes: Piton de La Fournaise $(2632 \mathrm{~m})$, in the southeastern area of the island, and Piton des Neiges ( $3070 \mathrm{~m})$, in the northwestern area. The latter is surrounded by three vast depressions with steep edges of more than $1000 \mathrm{~m}$ high, the so-called

Corresponding author address: Dr. Benjamin Pohl, Centre de Recherche de Climatologie, UMR6282 Biogéosciences, CNRS/ Université de Bourgogne Franche-Comté, 6 Boulevard Gabriel, 21000 Dijon, France.

E-mail: benjamin.pohl@u-bourgogne.fr
Cirques (calderas) of Mafate to the northwest, Salazie to the northeast, and Cilaos to the south (see locations in Fig. 2b). La Réunion holds most world records for intense rainfall amounts for time scales ranging from $12 \mathrm{~h}$ to 15 days due to the influence of tropical cyclones (TCs) developing over the SWIO. ${ }^{1}$ Over La Réunion, TCs are likely to cause heavy rainfall (e.g., $1825 \mathrm{~mm}$ in $24 \mathrm{~h}$ during TC Denise in early January 1966) due to the marked topography enhancing their effects (Barcelo et al. 1997). This recurrently produces torrential flash floods, landslides, and increased river and sediment flows that regularly cause fatalities and significant

\footnotetext{
${ }^{1}$ See http://www.nws.noaa.gov/oh/hdsc/record_precip/record_ precip_world.html.
} 

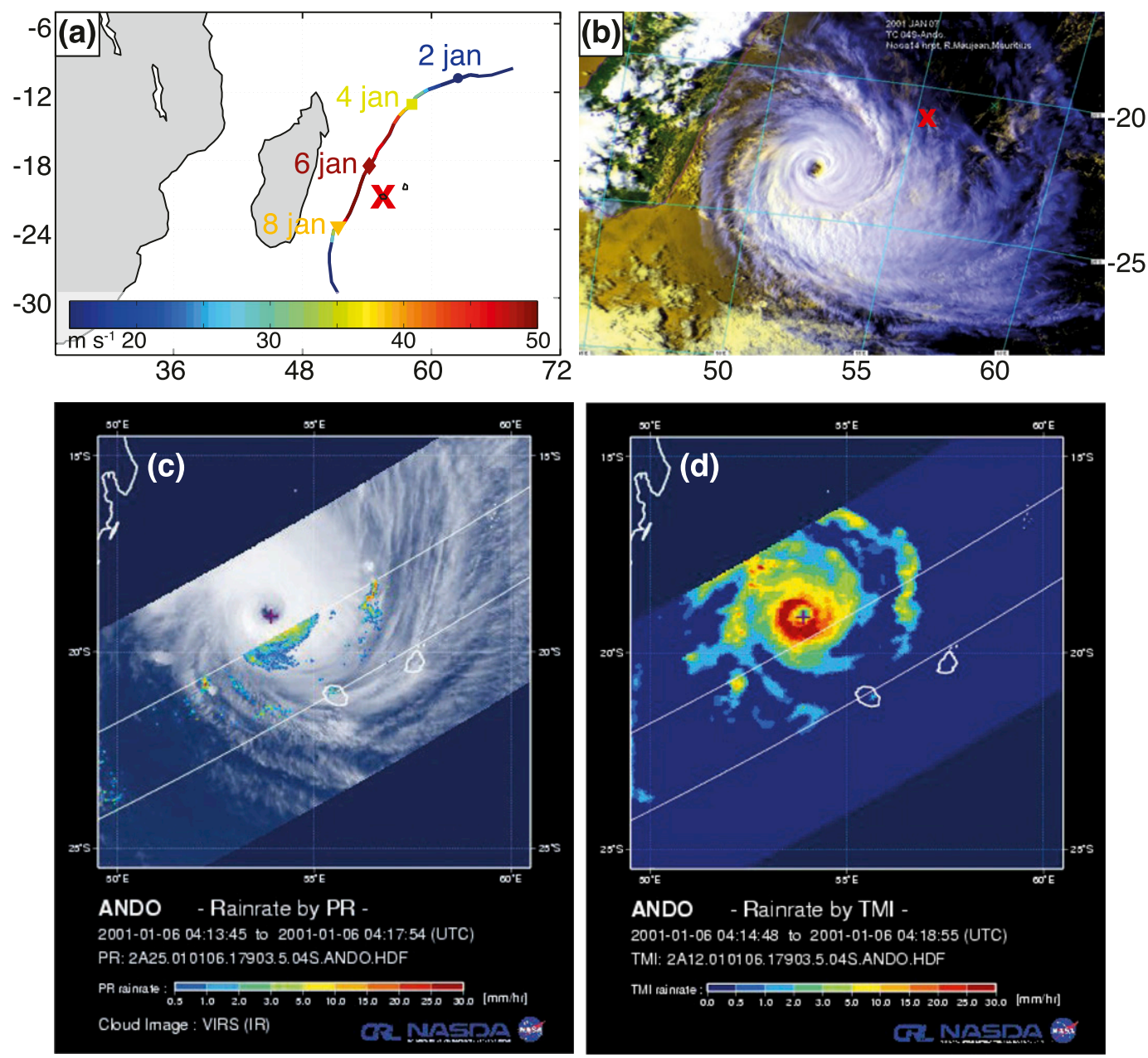

FIG. 1. TC Ando. (a) Maximum velocity from IBTrACS. (b) Ando at 1253 UTC 7 Jan 2001, as seen by the NOAA-14 satellite. (c) Visible image of TC Ando at 0418 UTC 6 Jan 2001, as seen by the visible channel of the Tropical Rainfall Measuring Mission (TRMM) satellite. (d) Corresponding instantaneous rainfall rate $\left(\mathrm{mm} \mathrm{h}^{-1}\right)$ as estimated by the TRMM Microwave Imager (TMI). In (a) and (b), the red $\times$ shows the location of La Réunion. Source: http://www.eorc.jaxa.jp/TRMM/typhoon/html/a/2001s/04S.ANDO_2001s_e.htm.

damage to infrastructure and crops. This issue is of importance to the island, given its dense population (840000 inhabitants, that is, 335 inhabitants per square kilometer on average), steep topography, and urbanized or volcanic soils, which are particularly prone to erosion.

Therefore, it is of primary importance to predict the life cycle of TCs over the SWIO in order to accurately anticipate their impacts on inhabited regions. To reach this objective, both accurate large-scale TC forecasts and appropriate downscaling techniques are needed to provide regionalized, finescale rainfall forecasts associated with the TC's evolution.

On the one hand, a great deal of effort has been spent on TC intensity forecasting in recent years, especially focused on improving numerical weather prediction models (DeMaria et al. 2014). However, the significant drop in track guidance forecast errors seen in the last decade has not been replicated with intensity guidance yet (Cangialosi and Franklin 2012; Falvey 2012; Mohapatra et al. 2013). In particular, anticipating sudden intensity changes of TCs remains a major operational and scientific issue, identified as a priority by the World Meteorological Organization's International Workshop on Tropical Cyclones (IWTC; WMO 2011, 2014). On the other hand, both statistical and dynamical downscaling techniques have attracted a large number of studies in the recent decades, notably motivated by the goal of regionalizing climate effects on environment and societies, including both abrupt events and climate change scenarios (e.g., Liu and Xie 2012; Daloz et al. 2015). Such an approach was followed by Morel et al. (2014, hereafter M14), who demonstrated the capability 

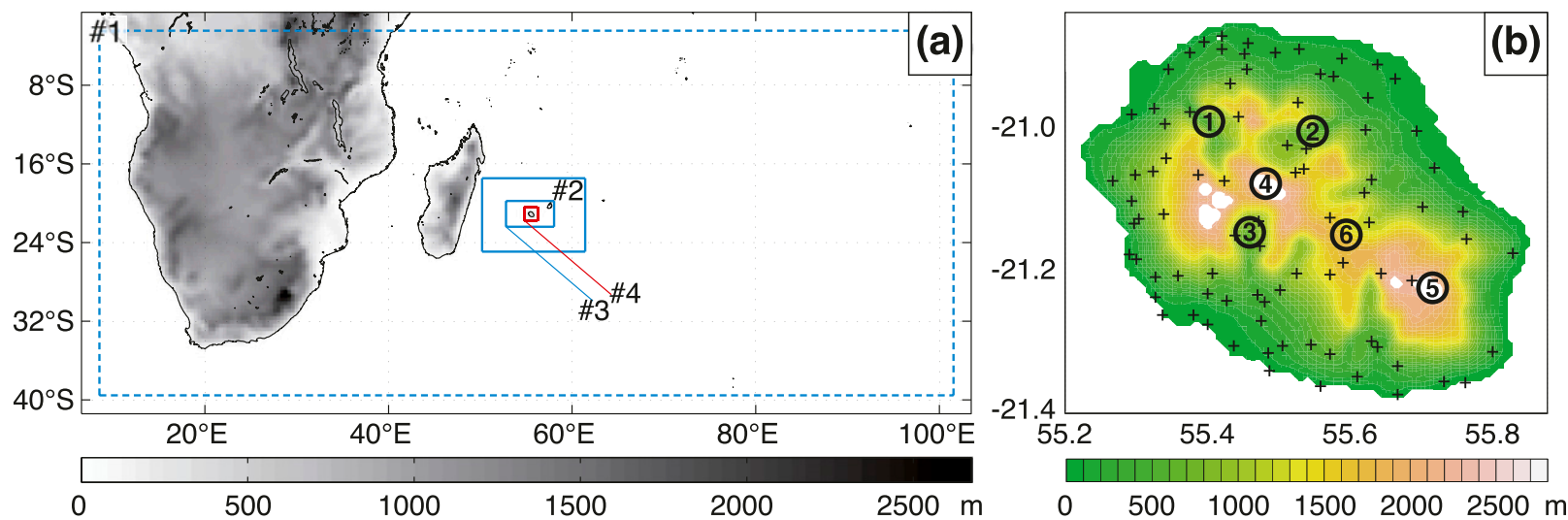

(c) Obs.

5 Jan
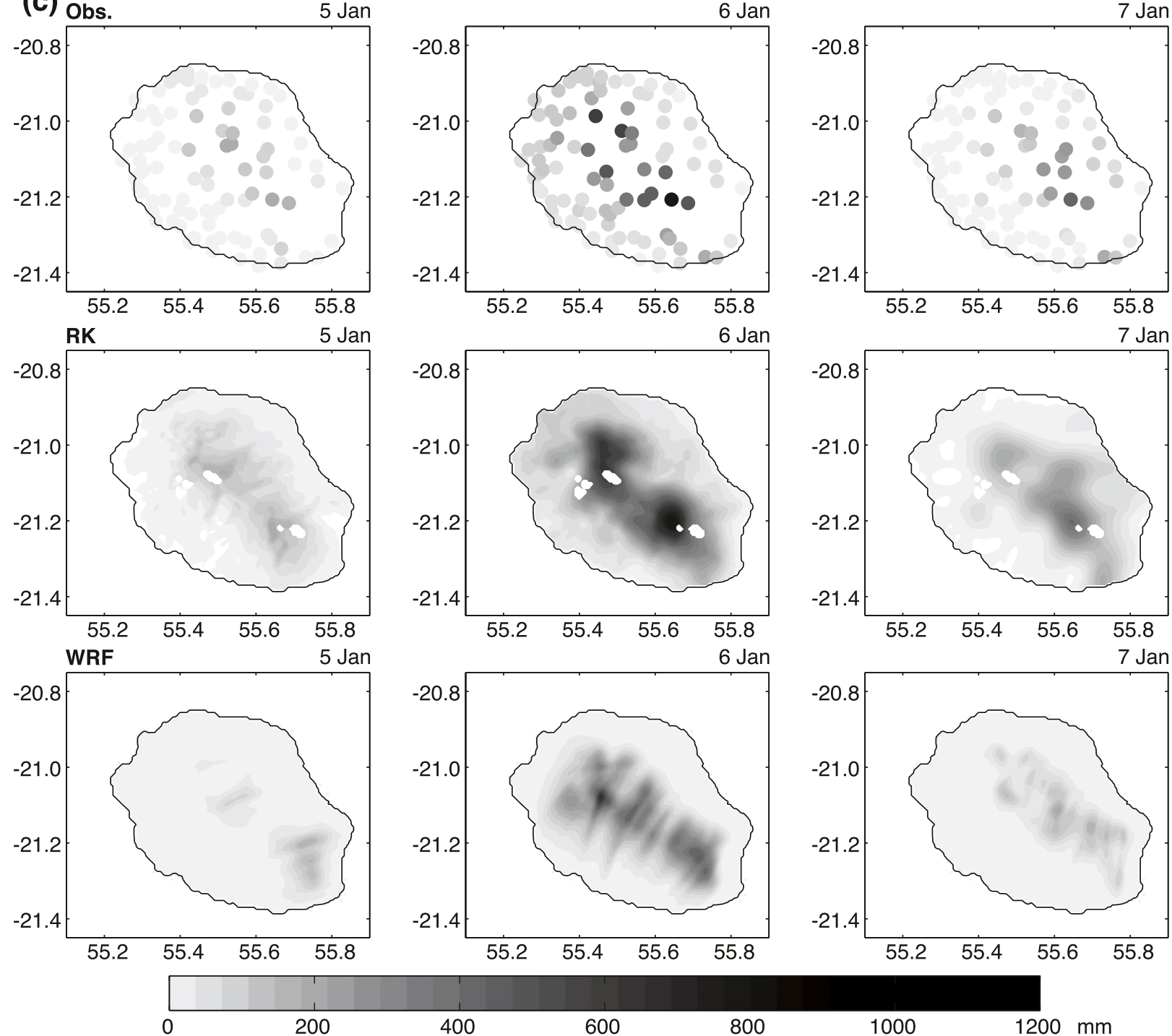

FIG. 2. (a) WRF domains. The outer dashed line corresponds to the limit of the buffer zone used to force domain 1 laterally with interpolated ERA-Interim data. The solid inner lines correspond to the limits of the nested domains, and the red lines show the location of inner domain 4. (b) Digital elevation model of La Réunion, such as it appears in WRF domain 4 at a 680-m horizontal resolution. The plus signs show the location of the available rain gauge stations. The numbers show the location of 1) Cirque of Mafate, 2) Cirque of Salazie, 3) Cirque of Cilaos, 4) Piton des Neiges, 5) Piton de la Fournaise, and 6) Plaine des Cafres. (c) Daily rainfall amounts (mm) for (from left to right) 5-7 Jan 2001, according to (first row) observations, (second row) kriged rainfall (RK), and (third row) WRF (domain 4). 
of the Weather Research and Forecasting (WRF) Model (Skamarock and Klemp 2008; Skamarock et al. 2008) to regionalize rainfall associated with the passage of a tropical cyclone near La Réunion at subkilometer-scale resolution $(680 \mathrm{~m})$. The good performance of the model was notably due to a nudging technique guiding the prognostic variables (wind, temperature, water vapor mixing ratio) toward the large-scale atmospheric configurations derived from the forcing ERA-Interim. The present work proposes to elaborate on the previous study of M14, by further quantifying the skill and biases of the model through forcing WRF with realistic largescale conditions (provided by ERA-Interim; Simmons et al. 2007; Dee et al. 2011). The aims of the present study are as follows:

(i) To quantify the skill and biases of the model to simulate rainfall amounts associated with a TC over La Réunion at subkilometer spatial resolution, including the uncertainties due to the numerical downscaling procedure, that is, by taking into account the internal variability (IV; Giorgi and $\mathrm{Bi}$ 2000; Separovic et al. 2008; Crétat et al. 2011) of the model through ensemble regional simulations.

(ii) To relate large-scale uncertainties concerning the TC life cycle (trajectory, distance to the island, intensity) to its local effects in terms of daily rainfall amount and spatial distribution.

To that end, and following M14, we consider the case study of TC Ando. Indeed, M14 documented the good skill of the WRF Model to regionalize associated rainfall at very high resolution $(680 \mathrm{~m})$ when used with a relaxation (or nudging) term in its prognostic equations. In the following, and in agreement with M14, ensemble simulations of TC Ando's life cycle are performed with nested domains simulating its effects over La Réunion. The uncertainties in the ensembles are ranked by interrupting the nudging at different phases of the TC life cycle, following the approach used in Pohl and Crétat (2014). This means that the model is constrained by the large-scale component of the atmospheric fields either only before the cyclogenesis or even during the early stages of the TC development. As the TC impacts La Réunion roughly one week after its genesis, seven nudging interruption dates are used to form a set of seven ensembles of five members each. The focus is then put on the local effects of the TC (in terms of wind speed and daily rainfall) over La Réunion, together with the associated uncertainties and errors.

This paper is organized as follows. Section 2 presents the case study, datasets, and methodologies, including the experimental setup for the model simulations. Section 3 is dedicated to the presentation of the results, at both regional (SWIO) and local (La Réunion) spatial scales, with special emphasis on scale interactions. Section 4 discusses the main results and briefly summarizes them.

\section{Data and methods}

\section{a. The case of TC Ando}

At its closest approach, TC Ando (31 December 2000-9 January 2001; Fig. 1) was located roughly $215 \mathrm{~km}$ northwest of La Réunion 1300 UTC 6 January. Ando was the first TC of the 2000-01 season in the SWIO basin. Its cyclogenesis occurred within the intertropical convergence zone (near $10^{\circ} \mathrm{S}, 64^{\circ} \mathrm{E}$ at 0600 UTC 31 December). Like most TCs forming in this area, Ando propagated southwestward, before turning southeastward during its decaying phase in the extratropical latitudes. According to the Regional Specialized Meteorological Center (RSMC) of La Réunion, in charge of tropical cyclone advisory and forecasting over the SWIO basin, Ando reached its maximum intensity on 6 January with estimated 10-min sustained wind speeds of $195 \mathrm{~km} \mathrm{~h}^{-1}\left(54 \mathrm{~m} \mathrm{~s}^{-1}\right)$ at the surface, wind gusts up to $75 \mathrm{~m} \mathrm{~s}^{-1}$ (corresponding to a category $4 \mathrm{TC}$ on the Saffir-Simpson hurricane wind scale), and an estimated central sea level pressure of $922 \mathrm{hPa}$. According to the Joint Typhoon Warning Center, however, Ando's intensity peak was reached one day earlier (5 January), with an estimated 1-min sustained wind speed of $\sim 220 \mathrm{~km} \mathrm{~h}^{-1}$ $\left(61 \mathrm{~m} \mathrm{~s}^{-1}\right)$. At this time Ando was located about $500 \mathrm{~km}$ north of La Réunion.

The daily rain gauge network over La Réunion is composed of 86 stations covering mostly the periphery of the island and with a lower density over the reliefs (Fig. 2b). Daily records indicate that the rainfall peak (up to $1200 \mathrm{~mm}$ in elevated sectors, and $190 \mathrm{~mm}$ on average over the whole island) associated with Ando occurred on 6 January. Low to moderate daily amounts were also recorded on 5 and 7 January inland. The rainfall peak occurred when the system reached its maximum intensity while located closest to the island. Corresponding kriged [regression kriging (RK)] fields (for further details see M14) show a very similar picture for these three days (Fig. 2c). As kriged fields are only computed for the range of altitudes documented by rain gauge stations, the white patches in Fig. $2 \mathrm{c}$ reflect the highest parts of the island. As stated in M14, the reliability of RK fields is strongly determined by the density of the rain gauge network, which decreases over the regions with the steepest topography (the slopes of the Cirques and the eastern flank of La Fournaise volcano). There, the interpretation of the RK fields should 
be made with caution. More generally, the RK fields are likely to smooth the rainfall field over La Réunion. Hence, local differences with model outputs should not be systematically considered as model errors.

\section{b. Model and experiments for dynamical downscaling}

Regional experiments are performed using the Advanced Research version of the nonhydrostatic Weather Research and Forecasting Model (WRF), version 3.5.1 (Skamarock et al. 2008). The model employs the same physical package as in M14: the Kain-Fritsch scheme for atmospheric convection (Kain 2004) using the trigger function developed by Ma and Tan (2009), the WRF single-moment 6-class graupel scheme for cloud microphysics (Hong and Lim 2006), and the Yonsei University parameterization of the planetary boundary layer (PBL; Hong et al. 2006). Radiative transfer is parameterized with the Rapid Radiative Transfer Model (Mlawer et al. 1997) for longwave radiation and the Dudhia (1989) scheme for shortwave radiation. Over land WRF is coupled with the four-layer Noah land surface model (Chen and Dudhia 2001a,b). Except for elevation data, which come from the Shuttle Radar Topography Mission (SRTM), all surface data are taken from the U.S. Geological Survey (USGS) database, which describes a 24-category land-use index based on climatological averages, and a 17-category Food and Agriculture Organization of the United Nations soil database, both available at $10 \operatorname{arc} \min (\sim 18.5 \mathrm{~km})$.

The regional domains consist of four two-way nested domains centered on La Réunion (Fig. 2a), at horizontal resolutions of $43.45 \mathrm{~km}$ (domain 1), $10.86 \mathrm{~km}$ (domain 2), $2.72 \mathrm{~km}$ (domain 3), and $680 \mathrm{~m}$ (domain 4), with 30 sigma levels in the vertical. In practice, domain 1 (resolving the whole TC's life cycle) and domain 4 (resolving its effects on La Réunion) are analyzed in detail, while domains 2 and 3 (necessary to smooth the transition across spatial scales) are given less attention. Deep atmospheric convection is explicitly resolved for domains 3 and 4 . Lateral forcing is provided every $6 \mathrm{~h}$ by ERA-Interim (Simmons et al. 2007; Dee et al. 2011) at a $0.75^{\circ}$ horizontal resolution and on 19 pressure levels. Sea surface temperature (SST) fields are prescribed every $24 \mathrm{~h}$ after a linear interpolation of monthly ERAInterim SST. Because this study is meant to be a downscaling exercise, a relaxation (nudging) approach is used to reduce the model's biases and IV (Pohl and Crétat 2014). Spectral nudging toward ERA-Interim horizontal winds (every $12 \mathrm{~h}$ ), and temperature and specific humidity (every $24 \mathrm{~h}$ ), is applied throughout domain $1\left(39.5^{\circ}-2.5^{\circ} \mathrm{S}, 8.5^{\circ}-101.5^{\circ} \mathrm{E}\right)$ and above the PBL. It retains wavelengths longer than $\sim 1000 \mathrm{~km}$, for which reanalyses are known to provide realistic solutions.
Simulations are carried out over an 11-day period extending from 29 December 2000 to 9 January 2001. Seven experiments are conducted with nudging interrupted at one of seven times: 0000 UTC 31 December (referred to as experiment N31), 0000 UTC 1 January (N01), 0000 UTC 2 January (N02), .., and 0000 UTC 6 January (N06). This allows the model to simulate either the large-scale synoptic configuration over the SWIO region or, in contrast, only small-scale features in constrained large-scale fields. Since data assimilation is not used in this study, and given the moderate nudging strength retained (just sufficient to ensure realistic largescale conditions), such a nudging protocol enables the model to simulate larger and more realistic TC intensities compared to ERA-Interim, due to its finer spatial resolution. For this reason, this protocol was preferred over an "initialization" protocol (i.e., with integrations of the model starting at one of seven times between 31 December and 6 January).

For each experiment (N31-N06), five-member ensemble simulations are performed, differing only by their initial conditions. The latter were obtained by initializing the model at 0000, 0600, 1200, and 1800 UTC 29 December and 0000 UTC 30 December, that is, in each case, a few hours or days before the cyclogenesis occurred. Model outputs are archived every $6 \mathrm{~h}$ from the beginning to the end of the simulations.

As stated by M14, who used the same model configuration, WRF accurately simulates the rainfall timing and totals associated with TC Ando over La Réunion (Fig. 2c). The spatial distribution of modeled precipitation is rather realistic as a whole, in spite of generalized dry biases mostly found in the highest regions. Noticeable exceptions are the eastern side of La Fournaise volcano and the two Cirques of Mafate and Salazie near Piton des Neiges, in the center of the island, where localized wet biases are obtained. In these regions it is difficult to properly assess the quality of WRF outputs, since the rain gauge network is sparser and the local RK estimations in these areas are mostly based on statistics (see M14 for more details). Roughly similar patterns, albeit smaller in amplitude, are also found for 5 and 7 January.

\section{Results}

\section{a. Ando life cycle}

Figure 3 presents the trajectories simulated by the successive WRF ensembles. These trajectories are determined using the Commonwealth Scientific and Industrial Research Organisation (CSIRO) detection method developed by Walsh (1997). We also apply this detection scheme to the ERA-Interim fields (used to 

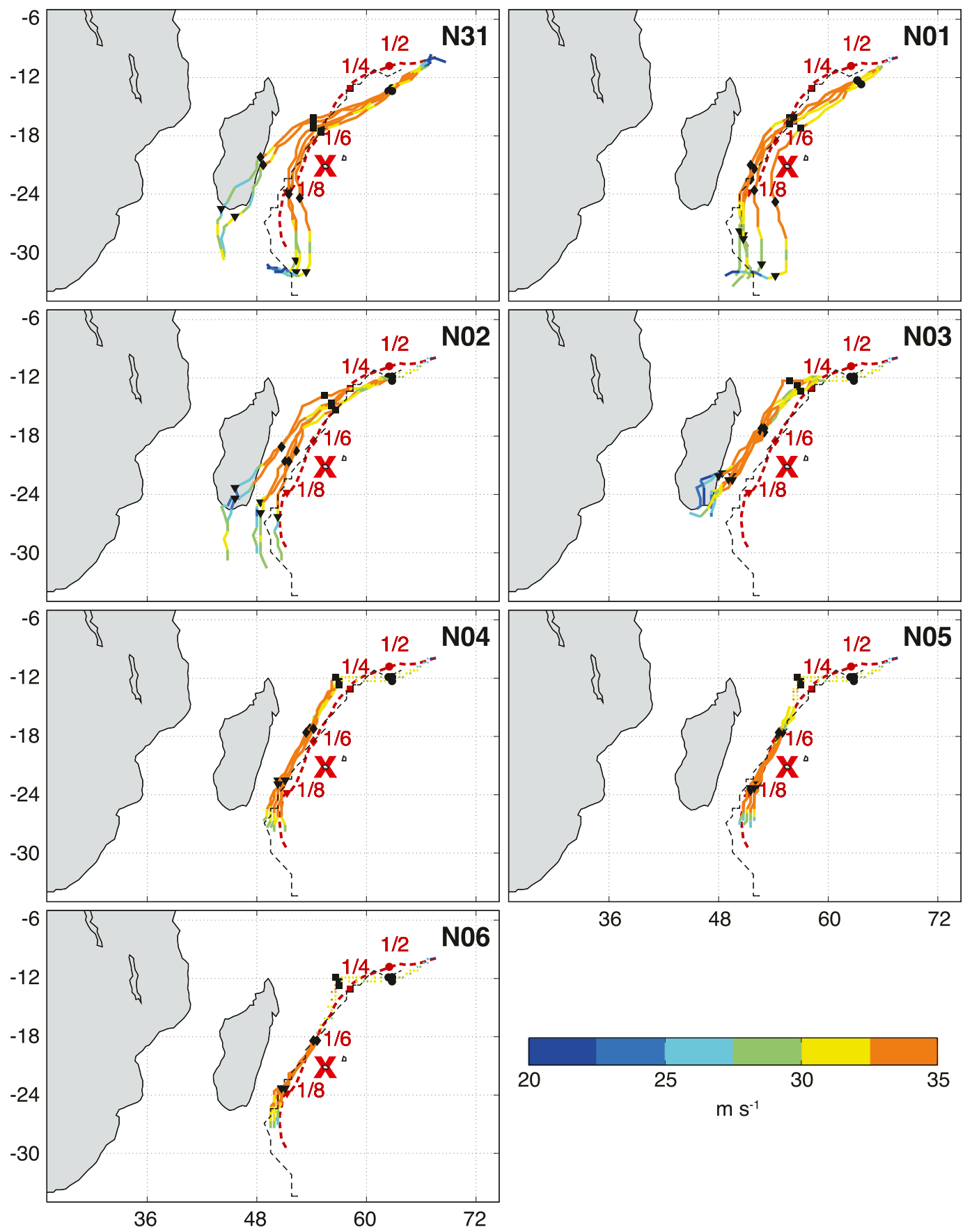

FIG. 3. Ensemble WRF simulations of TC Ando's trajectories. The intensity of the cyclone, as inferred by the maximum velocity of the horizontal wind, is indicated by the color scale. The trajectories and TC intensities are calculated based on WRF domain 1 . The interruption date of the nudging is labeled in the figure, and the trajectory simulated during the nudging period appears as dotted curves. The red trajectory corresponds to IBTrACS observations, with the dates labeled in red indicating the TC's propagation; the dashed black trajectory is that derived from ERA-Interim. The red $\times$ shows the location of La Réunion.

force and nudge WRF) at $0.75^{\circ}$ resolution. We then compare the tracks and intensities of TC Ando as simulated by WRF and ERA-Interim with the National Climatic Data Center's International Best Track Archive for
Climate Stewardship (IBTrACS; Knapp et al. 2010). This dataset merges TC data from different operational centers around the world. In this study, we use data provided by RSMC La Réunion. 

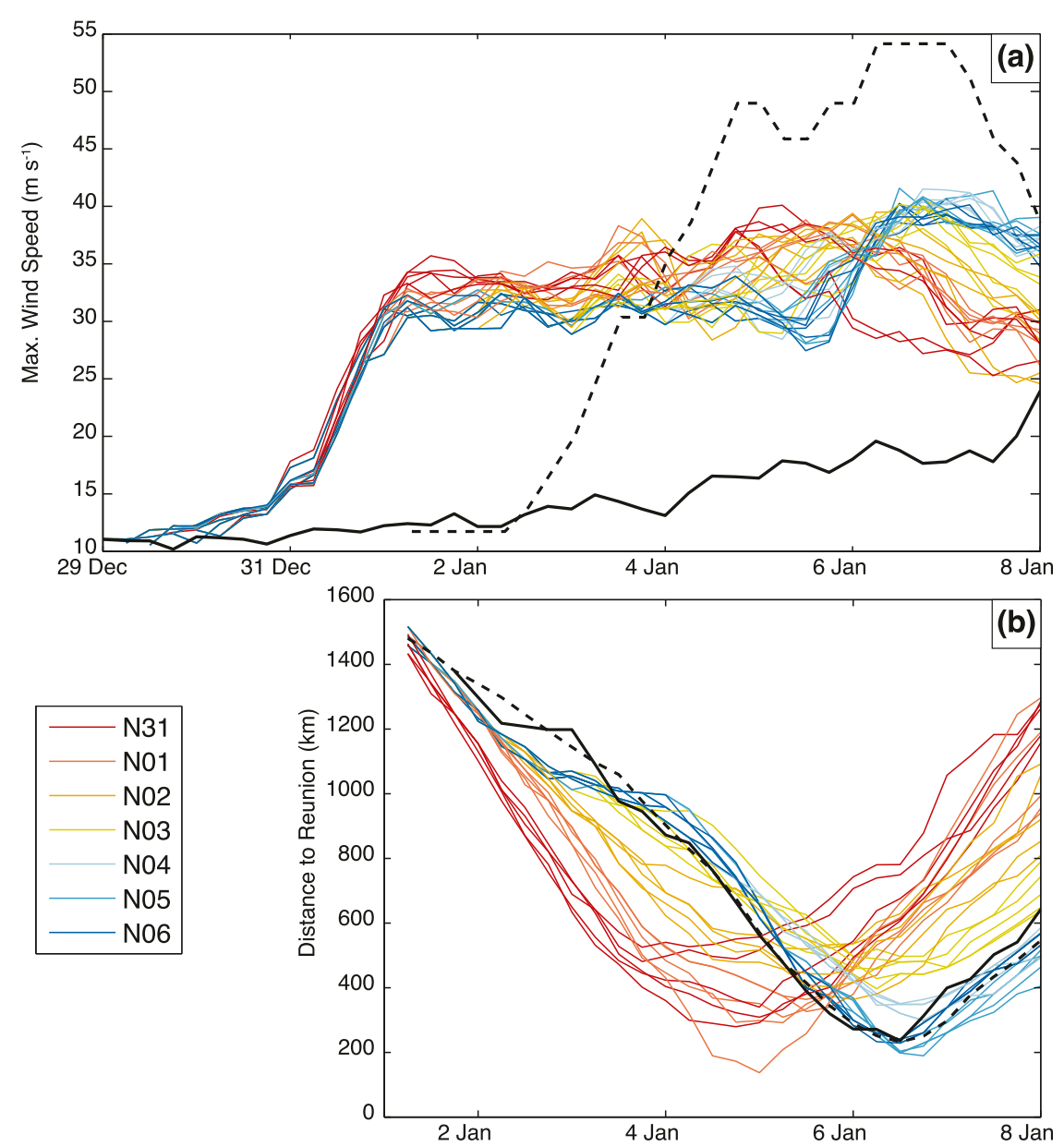

FIG. 4. (a) Maximum wind speed $\left(\mathrm{m} \mathrm{s}^{-1}\right.$ ) simulated by WRF domain 1 (color curves: five members for each ensemble simulation), National Climatic Data Center's IBTrACS (dashed black curve), and ERA-Interim at $0.75^{\circ}$ horizontal resolution (solid black curve), between 1 and 8 Jan. (b) As in (a), but for the distance to La Réunion (km).

Each ensemble includes five members and the ensembles differ in the date of interruption of the nudging (i.e., in the fraction of the TC's life cycle prescribed to the model, compared to that simulated by the model, shown as dashed and solid curves, respectively, in Fig. 3). In all ensembles, the simulated track is rather close to observations (and to that derived from the reanalysis), indicative of a strong large-scale control on the TC's life cycle. In other words, the WRF-simulated TC develops only a moderate IV. This can be surprising, since lateral boundary conditions are prescribed along the boundaries of the larger domain (Fig. 2a), a few thousand kilometers away from the TC itself. As expected, the uncertainties and errors in the simulated track are much larger for the experiments with early nudging interruptions. In N31 for instance (nudging ending on 31 December), the TC is likely to reach the eastern coast of Madagascar according to two members, while the remaining three members simulate a track farther east, closer to the Mascarene islands. The spread among the possible trajectories gradually decreases, as the nudging lasts longer. In ensembles with a nudging ending on 2-4 January, the model tends to locate the TC too far west, resulting in tracks decaying over southern Madagascar. This track error strongly decreases for the next ensembles (5 and 6 January).

Whatever the nudging interruption date and except for the TC tracks making landfall over Madagascar, all simulated TC intensities are strongly reproducible from one member to another, with gusts peaking at 35$40 \mathrm{~m} \mathrm{~s}^{-1}$ (versus $55 \mathrm{~m} \mathrm{~s}^{-1}$ in the observation and $20 \mathrm{~m} \mathrm{~s}^{-1}$ in ERA-Interim). Because of the finer resolution of the first WRF domain $(\sim 43 \mathrm{~km})$ compared to the forcing reanalysis $(\sim 80 \mathrm{~km})$, the intensity of the TC is sensibly closer to the observations.

Figure 4 summarizes the spread in the temporal evolutions of the TC intensity and distance to the island. 
When the model solution is not guided toward the reanalyses during the whole life cycle of the TC, largescale uncertainties develop and strongly alter the simulated intensity (Fig. 4a) and trajectory (Fig. 3). As the nudging lasts longer, these properties gradually converge toward the observation, and simulated highresolution rainfall over La Réunion gains in accuracy. This is because model errors and uncertainties can develop only at small scales, since large-scale fields are prescribed. However, it appears from Fig. 4 that the simulated intensity of the TC, as monitored by surface wind speed, is strongly dependent on the model's resolution, making the results derived from IBTrACS, $0.75^{\circ}$-resolution ERA-Interim and 43-km WRF simulations (i.e., for domain 1), hardly comparable. It is nonetheless clear that both models fail at simulating a realistic intensification phase of the TC (too late in ERA-Interim but too early in WRF with errors that are highly reproducible among the members in our ensembles).

While the interpretation of these errors is beyond the scope of the present study, they question the extent to which realistic effects of the TC over La Réunion can be obtained at finescales in spite of unrealistic TC structures at larger scales. This could be the case, for instance, if the orographic forcing is predominant locally upon the TC characteristics to explain its impacts over the island.

\section{b. Local rainfall over La Réunion}

Figures 5-9 show the high-resolution daily rainfall simulated over La Réunion by the WRF ensembles. As an illustration of the local uncertainties between the ensemble members, Fig. 5 details the intermember spread of a single numerical experiment, N01 (for which the relaxation ends on 1 January). Associated parameters concerning the simulated TC properties are also given. Figures $6-8$ show the ensemble means, standard deviation, and ensemble mean errors against kriged observations (RK field, shown in Fig. 2c), respectively. Table 1 extracts the largest daily rainfall amounts in the same datasets. For WRF simulations, the spread of the values inside each ensemble is estimated by presenting extreme and median values. Finally, Fig. 9 presents the probability of heavy rainfall [excesses over the $20 \mathrm{~mm}$ $(6 \mathrm{~h})^{-1}$ threshold] for selected stages of the TC life cycle according to the two inner WRF domains. This helps in (i) assessing the local versus regional scale organization of the rainfall field, (ii) illustrating the uncertainties in the TC location and morphology between the members, and (iii) documenting the occurrences of rainy bands potentially modulating the simulated rainfall field over La Réunion.
WRF simulates rather large rainfall amounts (exceeding $1000 \mathrm{~mm}$ in elevated regions) one day too early (5 January instead of 6 January) in the N31 and N01 ensembles (Fig. 6; Table 1). This timing error is due to a too rapid and direct propagation of the simulated TC toward the southwest, from the region of cyclogenesis (roughly $10^{\circ} \mathrm{S}, 70^{\circ} \mathrm{E}$ ) toward the Mascarene region (Fig. 3). This time shift in the simulated rainfall peak appears as marked wet biases for 5 January in Fig. 8, since the observed rainfall amounts for 5 January exceeds barely $100 \mathrm{~mm}$ in the central parts of the island (Fig. 2c). These wet biases are followed by strong dry biases on 6 January. Largest uncertainties (i.e., disagreements from one member to another; Fig. 7) are located in the elevated regions of the western part of La Réunion (for N31) or along the western slopes of the island (for N01). In the latter case, uncertainties are actually due to a single member, 5 , associated with heavy rainfall $(>1000 \mathrm{~mm})$ in the western part of La Réunion (Fig. 5; Table 1). Indeed, the TC is closest to the island in this member $(137 \mathrm{~km}$ instead of $292-364 \mathrm{~km}$ for the other members; Figs. 5 and 9c). For comparison purpose, the driest and median members simulate between 550 and $700 \mathrm{~mm}$ of precipitation (Table 1). In this case, large-scale errors in the simulated TC life cycle and trajectory (i) result in timing errors for the local rainfall variability, and (ii) cause local errors and uncertainties in the simulated rainfall amounts and distribution, depending on the cyclone's location with respect to La Réunion (Figs. 3 and 9a-d).

As expected, the error in the TC location decreases as the nudging duration increases (Fig. 3). As a consequence, one can also notice that the model gradually converges toward a more realistic phasing of the main rainfall peak (i.e., the timing errors noted for N31 and N01 are mostly corrected). Thus, the strongest uncertainties in the following experiments correspond to the largest amounts reached locally over the island, mostly in its central, elevated parts. Indeed, detailed analysis of the individual members (not shown) reveals that the spatial distribution of daily rainfall and the associated amounts strongly varies from one member to another, although local maxima in the daily rainfall show rather moderate intermember discrepancies (Table 1). Schematically, the local-scale rainfall increases as the distance between the simulated TC and the island decreases (not shown); this is particularly verified for ensemble N02, characterized by strong intermember disagreements in both the TC tracks (Fig. 3) and local rainfall (Fig. 7).

The N02-N04 WRF ensembles all simulate too dry conditions over La Réunion according to the ensemble mean (Fig. 6).

- In N02, this conceals marked uncertainties from one member to another on 6 and 7 January (Fig. 7), resulting 

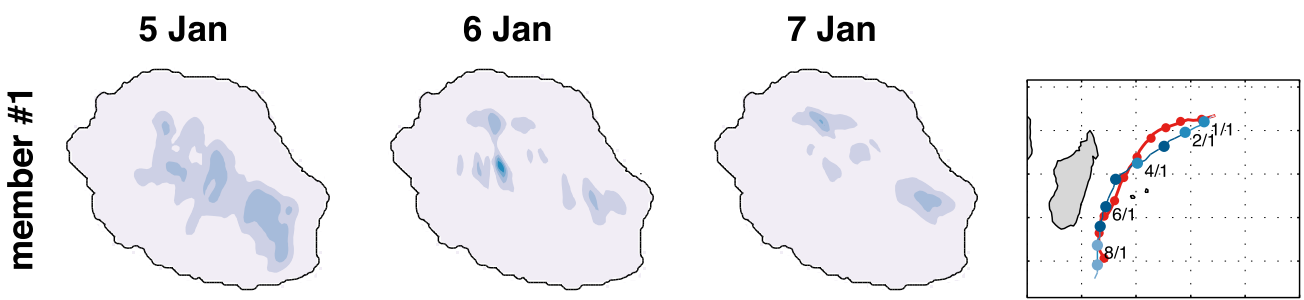

04-Jan-2001 06:00:00 Distance $=309 \mathrm{~km}$ Azimuth $=179$ degrees $\mathrm{MSLP}=965 \mathrm{hPa}$ Vorticity $=-110^{-5} \mathrm{~s}^{-1}$ Wind $=33 \mathrm{~m} \cdot \mathrm{s}^{-1}$
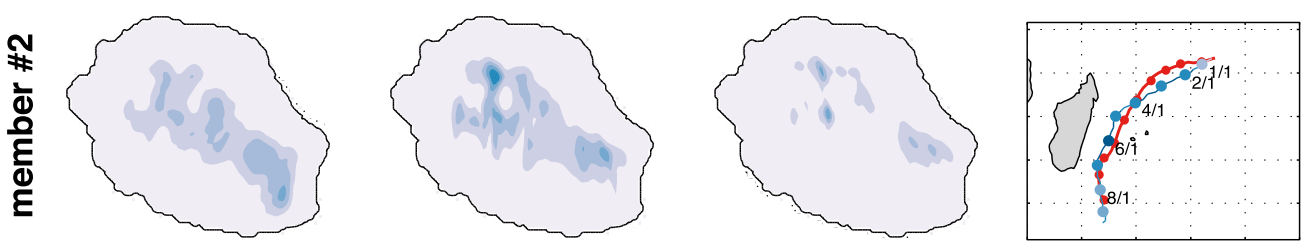

04-Jan-2001 18:00:00 Distance $=326 \mathrm{~km}$ Azimuth $=156$ degrees $\mathrm{MSLP}=965 \mathrm{hPa}$ Vorticity $=-2.710^{-5} \mathrm{~s}^{-1}$ Wind $=33 \mathrm{~m} . \mathrm{s}^{-1}$
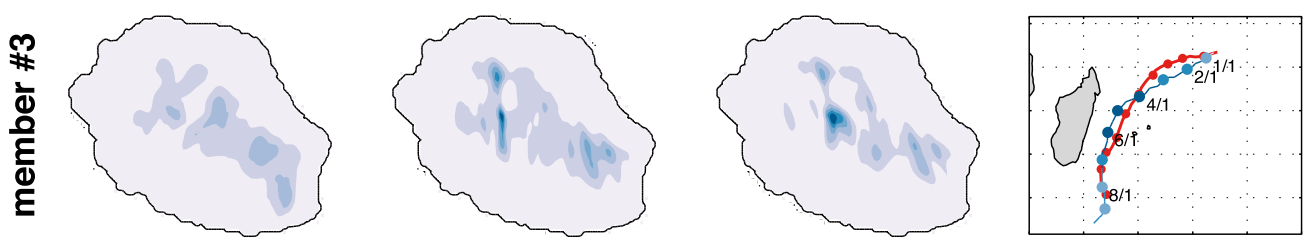

04-Jan-2001 18:00:00 Distance $=364 \mathrm{~km}$ Azimuth $=156$ degrees $\mathrm{MSLP}=960 \mathrm{hPa}$ Vorticity $=-2.110^{-5} \mathrm{~s}^{-1}$ Wind $=35 \mathrm{~m} \cdot \mathrm{s}^{-1}$
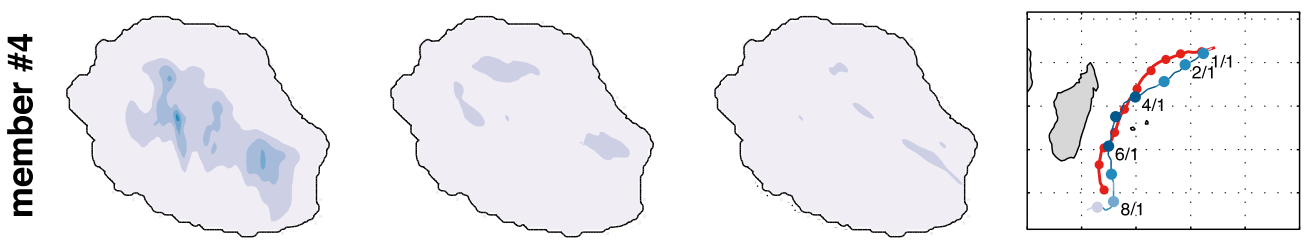

04-Jan-2001 12:00:00 Distance $=292 \mathrm{~km}$ Azimuth $=159$ degrees $\mathrm{MSLP}=953 \mathrm{hPa}$ Vorticity $=-2.310^{-5} \mathrm{~s}^{-1}$ Wind $=35 \mathrm{~m} \cdot \mathrm{s}^{-1}$
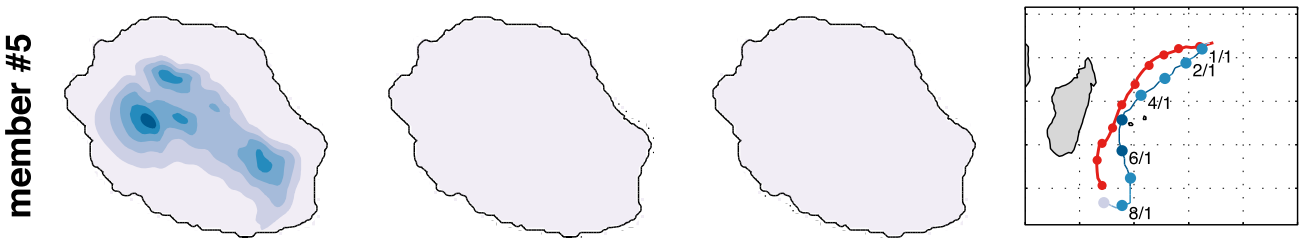

04-Jan-2001 06:00:00 Distance $=137 \mathrm{~km}$ Azimuth $=193$ degrees $\mathrm{MSLP}=961 \mathrm{hPa}$ Vorticity $=-3.810^{-5} \mathrm{~s}^{-1}$ Wind $=34 \mathrm{~m} \cdot \mathrm{s}^{-1}$

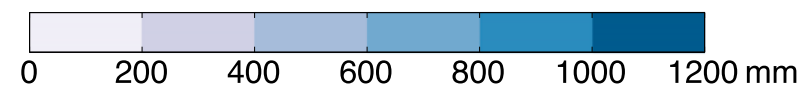

FIG. 5. N01 WRF ensemble simulations. (left) Daily rainfall amounts (mm) in La Réunion for (from left to right) 5-7 Jan 2001 and (from top to bottom) the five members, as simulated by WRF domain 4. (right) Corresponding simulated TC trajectory (blue; red from IBTrACS) and intensity for each member, together with basic statistics of the TC when it is closest to La Réunion (corresponding date, minimum distance to La Réunion, and synchronous TC intrinsic properties, including sea level pressure, vorticity, and wind speed), obtained from WRF domain 1.

in strong discrepancies in terms of maximum daily rainfall amounts (Table 1). The members simulating a TC reaching Madagascar (in N02 but also N31 and N03: see Fig. 3) are logically the driest over La Réunion, since the system stays located too far from the island. Nonetheless, nonnegligible uncertainties remain in the three other members in spite of rather grouped trajectories. This suggests that either the distance between the TC and the island or the TC intrinsic properties (intensity, morphology, rainy bands) may vary from one member to another, thus strongly modifying the amplitude of the local rainfall peak. Such uncertainties in the TC are illustrated in Fig. 9e (along the western boundary of the domain) and cause nonnegligible local uncertainties close to La Réunion. On the one hand, rainy bands appear as strongly irreproducible from one member to another. On the other hand, although enhanced rainfall over La Réunion is reproduced by all members, perturbations induced by the topography favor the development of precipitation downstream of the island compared to the dominant fluxes, but this feature is simulated by only two members out of five (Fig. 9f).

- The dry biases in N03 and N04 (Figs. 6 and 8; Table 1) are more uniform from one member to another 

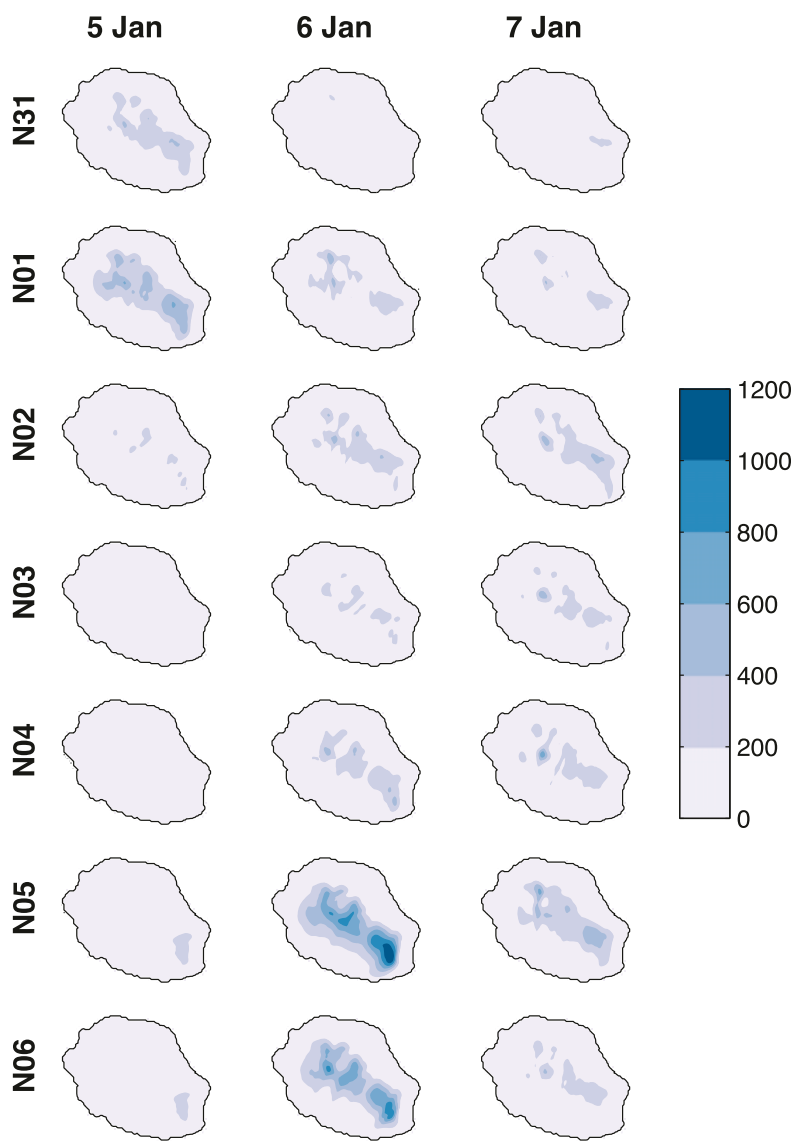

FIG. 6. Ensemble mean simulation of daily rainfall amounts (mm) in La Réunion for (from left to right) 5-7 Jan 2001, for (from top to bottom) the seven ensemble simulations (N31-N06), as simulated by WRF domain 4 .

(Fig. 7), and thus more reproducible. This is due to smaller errors in the location of the TC (Fig. 3), which systematically remains too far from La Réunion (Figs. 9g and 9h). N04 simulates more realistic and more reproducible tracks (Fig. 3). At this stage (and unlike the simulations discussed above), the uncertainties in the TC life cycle concern more its morphology than its location (e.g., Fig. 9h, to be compared with Figs. 9c and 9d); this results in well-phased and reproducible local rainfall peak (Figs. 6 and 7; Table 1) but too small in amplitude (Fig. 8).

In ensembles N05 and N06, the large-scale uncertainties associated with the TC are sensibly reduced (Figs. 9i-p). In N05 the location of the TC remains weakly variable from one member to another, as can be seen from the location of the eye (Figs. 9j and 9k). In N06 all members produce similar locations (Fig. 9n) and the IV of the model mostly concerns the morphology of the system (Fig. 9n) and/or the presence of rainy bands on its eastern flank (Figs. 9o and 9p). The relief of the island
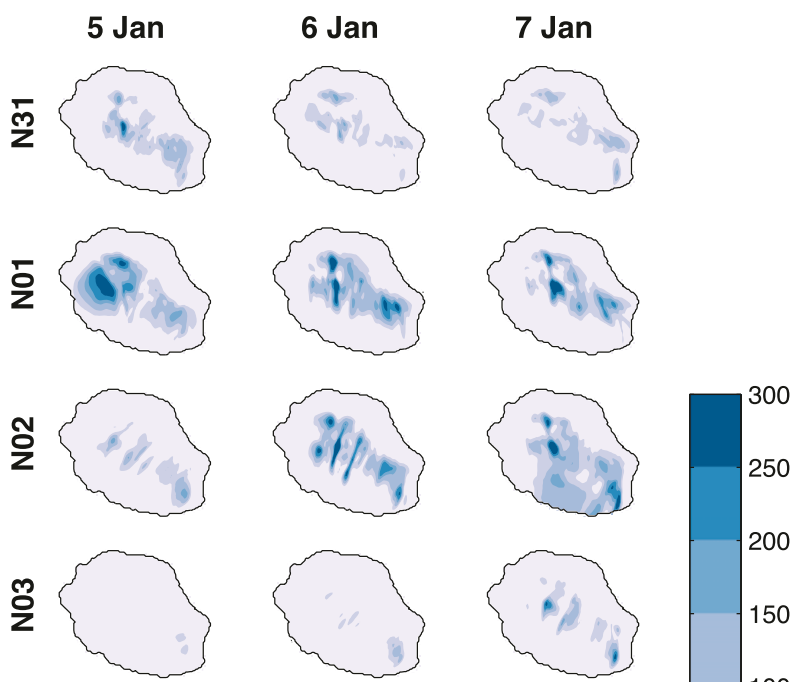

$-200$
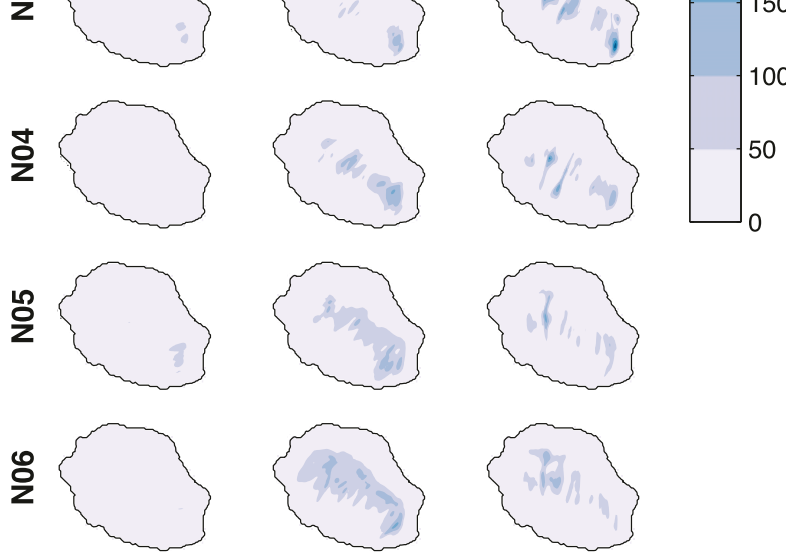

FIG. 7. As in Fig. 6, but for the intermember standard deviation (mm).

also causes chaotic flow downstream of the relief, which modulates rainfall amounts there. Locally, the rainfall peak over La Réunion is correctly phased with observations (Figs. 2c and 6). It reaches realistic maximum values (Table 1) in spite of persisting errors in the spatial distribution (Fig. 8). The eastern slopes of La Fournaise volcano, which are usually the wettest parts of the island due to their location facing the dominant trade winds (M14; Barcelo and Coudray 1996), also concentrate significant wet biases. This is also the case for the abrupt topography around the "Cirques" of Salazie in the northeast and Mafate in the west (see Fig. 2b for their locations). In sharp contrast, lower regions, such as the "Plaine des Cafres" on the western flank of the volcano, and the coastal plains of the whole island show marked dry biases. This suggests a too strong spatial variability and too strong vertical gradients in the simulated rainfall field. This point was already discussed in detail in M14, the spatial distribution of simulated rainfall amounts being highly sensitive to the horizontal resolution of the model (N. Yu et al. 2014, unpublished manuscript). As expected, largest uncertainties (Fig. 7) correspond to the 

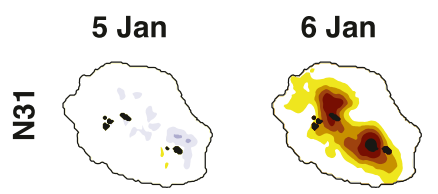

7 Jan
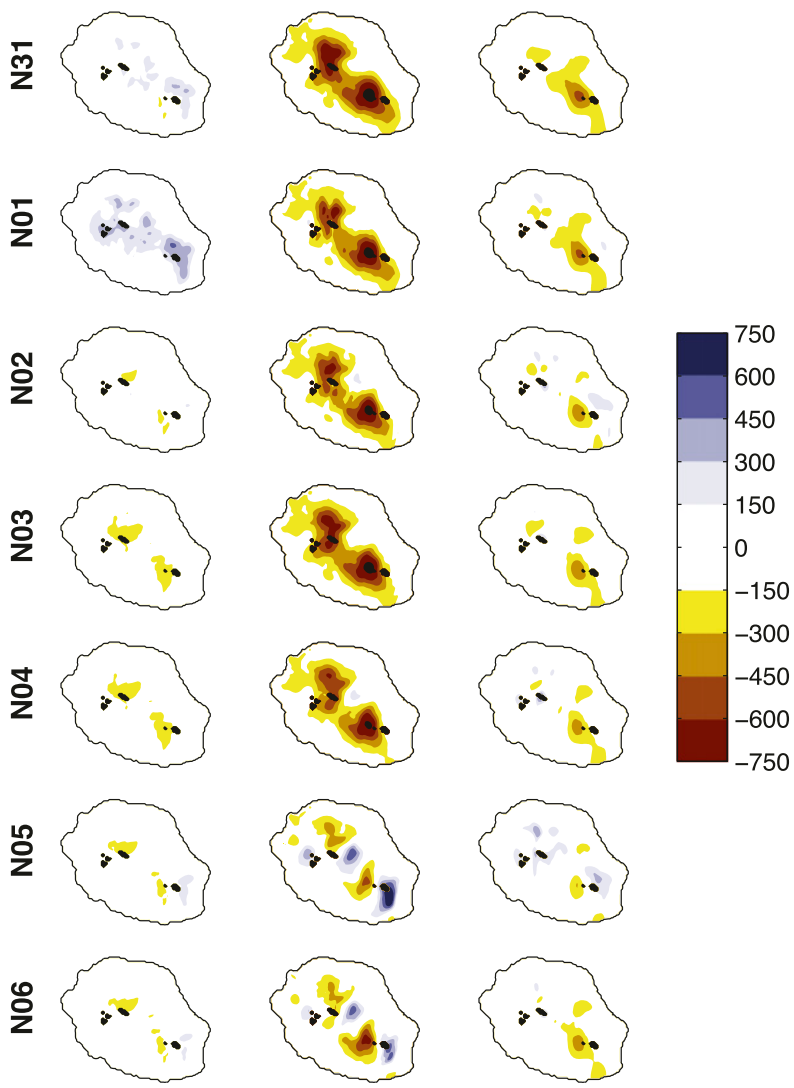

FIG. 8. As in Fig. 6, but for the simulated rainfall differences (mm) against RK fields.

regions experiencing the largest daily rainfall amounts. They have a clear tendency to locate over the northeastern flanks of the relief. Such uncertainties could relate (i) to moderate errors in the distance separating Ando from the island (spreading from 229 to $241 \mathrm{~km}$ from one member to another) and (ii) to associated vorticity and modulus of the lower-level wind (spreading from -1.1 to $-5.9 \times 10^{-5} \mathrm{~s}^{-1}$ and from 28 to $34 \mathrm{~m} \mathrm{~s}^{-1}$, respectively, from one member to another). The member simulating the strongest vorticity is also that closest to the island: these two parameters favor stronger northeasterly winds, thereby bringing sensibly larger rainfall over the northeastern part of the island (not shown). Thus, the direction and strength of the incoming winds appear as a key factor in the spatial distribution of high-resolution rainfall over the island.

\section{c. Local wind over La Réunion}

This section focuses on the simulated wind and moisture fluxes in the neighborhood of the island, in order to (i) assess the rain-causing processes and mechanisms and help interpret the rainfall amounts, distribution, errors, and uncertainties discussed above; and (ii) characterize the uncertainties in the lowerlevel horizontal moisture fluxes, likely to cause, together with heavy rainfall, important material damages and fatalities.

Figure 10 presents the $10-\mathrm{m}$ horizontal moisture fluxes ensemble mean and intermember spread for each ensemble experiment close to La Réunion. Figure 11 shows the same diagnostics for the vertical velocity at $500 \mathrm{hPa}$. These fields were respectively chosen because they infer lower-level moisture advections associated with the TC and deep ascending motion in the midtroposphere, predominately due to local orographic forcing.

Strong moisture fluxes prevail in the lower layers of the troposphere (Fig. 10a). Wind modulus is generally comprised between 5 and $20 \mathrm{~m} \mathrm{~s}^{-1}$ close to the island and even $25-30 \mathrm{~m} \mathrm{~s}^{-1}$ when the TC reaches its closest location to La Réunion (on 5 January for N31 and N01, and 6 January for N05 and N06). These values are rather close to in situ measurements (roughly $19 \mathrm{~m} \mathrm{~s}^{-1}$ along the north coast but up to $37 \mathrm{~m} \mathrm{~s}^{-1}$ in the elevated region of Plaine des Cafres, both recorded on 6 January, when Ando reached its closest position to the island). Depending on the relative azimuth between the TC and the island, changing from north to east, flow direction also shifts from easterly to northerly. Laminar flows are found upstream of La Réunion with moderate uncertainties (Fig. 10b). Over La Réunion and downstream, the horizontal flux velocities abruptly decrease, in line with orography-forced uplift and terrain blocking. The intermember spread also reaches much larger values there (Fig. 10b), indicative of strongly chaotic/ irreproducible small-scale turbulent features, caused in the wind by the topography (for more details on the internal variability in mesoscale simulations, please refer to, e.g., Alexandru et al. 2007; Separovic et al. 2008; Crétat et al. 2011; among the many papers dedicated to this issue). This is also consistent with the IV in the rainfall field shown in Figs. 9o and 9p.

In the middle troposphere, the main deep-convective upward motion is restricted to the air column over the island itself (Fig. 11a), with very strong ascents at the vertical of the elevated areas and subsidence on the leeward side of the main mountainous ranges (and more generally, downstream of the island). This shows that, for this case study, the extreme rainfall found over La Réunion is associated with local uplift rather than being embedded in large-scale rain-bearing systems. This is clearly visible on satellite images (Figs. 1c and 1d), that is, on 6 January, during the observed rainfall peak over the island (Fig. 2). 
(a) N31 1/5 OUTC

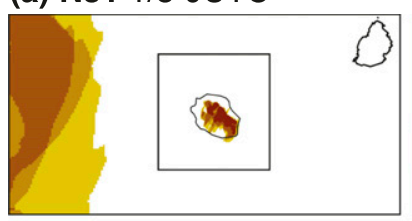

(e) N02 1/5 18UTC

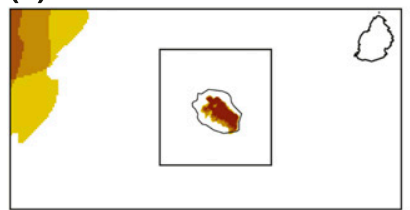

(i) N05 1/6 6UTC

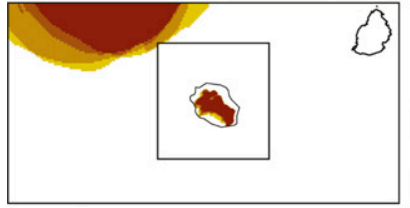

(m) N06 1/6 6UTC

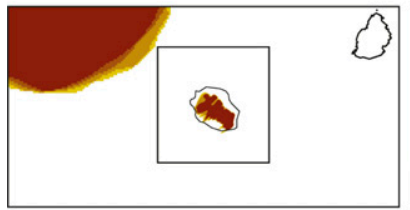

(b) N31 1/5 6UTC

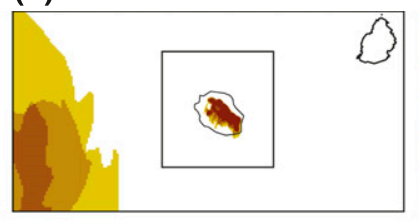

(f) N02 1/7 OUTC

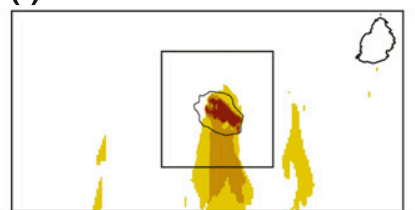

(j) N05 1/6 12UTC

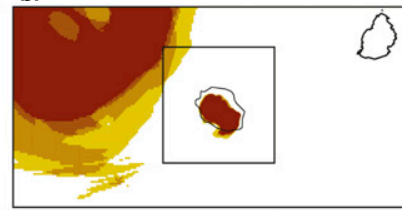

(n) N06 1/6 12UTC

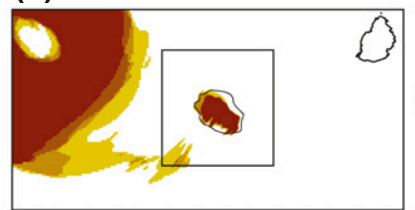

(c) N01 1/5 6UTC

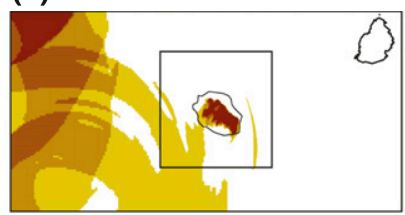

(g) N03 1/5 OUTC

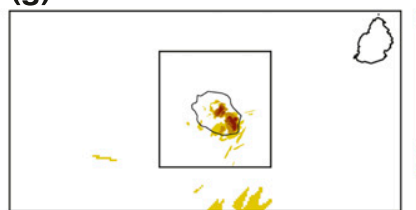

(k) N05 1/6 18UTC

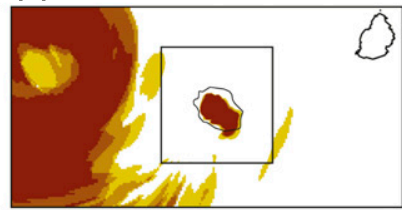

(o) N06 1/6 18UTC

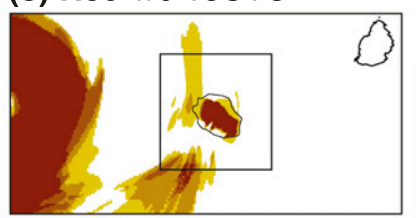

(p) N06 1/7 OUTC

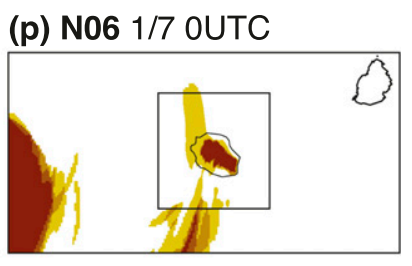

(d) N01 1/5 12UTC

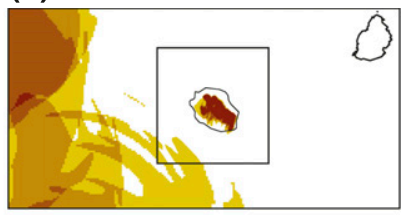

(h) N04 1/7 OUTC

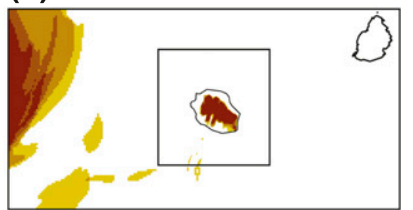

(I) N05 1/7 OUTC

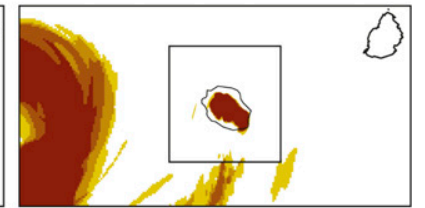

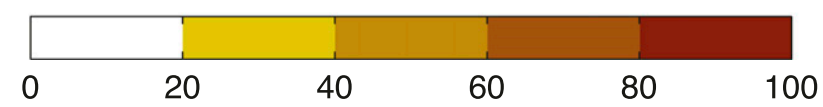

100

FIG. 9. Probability (\%) of exceeding the threshold of $20 \mathrm{~mm}$ in $6 \mathrm{~h}$ for selected ensemble simulations and at various dates between 5 and $7 \mathrm{Jan} 2001$. The name of the experiment and the time window are labeled in the figure (rainfall amounts are computed between the labeled time $t$ and $t+6 \mathrm{~h})$. The outer rectangle corresponds to WRF domain 3 (2.72-km resolution) and the inner domain to domain 4 refinement (680-m resolution).

This also indicates that the free-atmosphere dynamics is not involved in the southwest to northeast rainfall alignments noticed, for instance, in Figs. 2c, 6, and 7 (although the latter are clearly parallel to the low-level prevailing flow). These lines could possibly be due to exaggerated boundary layer rolls, a hypothesis that cannot be fully addressed given the rather low model output frequency (every $6 \mathrm{~h}$ ). Further tests are needed to address this issue properly.

\section{d. Estimating the orographic forcing}

The results of section $3 \mathrm{c}$ show that the heavy rainfall over La Réunion (Table 1) is caused by strong moisture-laden flows associated with the TC that are forced to ascend over the island, confirming the hypothesis of a strong orographic effect. This implies that the topographic features (slopes, elevation, orientation against the wind) strongly influence the spatial distribution of rainfall amounts over the island. We aim here at quantifying the fraction of rainfall spatial variability that can be explained by surface conditions derived from the digital elevation model used in WRF and for the computation of kriged (RK) fields.

TABLE 1. Largest daily rainfall amount $(\mathrm{mm})$ over La Réunion according to rain gauge records (Obs), kriged fields (RK), and WRF ensemble simulations (N31-N06), for 5-7 Jan. For each ensemble, the three values correspond to the (left) minimum, (middle) median, and (right) maximum value according to the five members. Values smaller than $200 \mathrm{~mm}$ (larger than $1000 \mathrm{~mm}$ ) appear in italic (boldface) font.

\begin{tabular}{lrrrrrrrrr}
\hline & \multicolumn{3}{c}{5 Jan } & \multicolumn{3}{c}{ 6 Jan } & \multicolumn{3}{c}{ 7 Jan } \\
\hline Obs & 263 & & & $\mathbf{1 3 1 0}$ & & & 560 & \\
RK & 303 & & & $\mathbf{1 2 7 3}$ & & 558 & \\
N31 & 314 & 550 & 954 & 112 & 328 & 489 & 239 & 398 & 468 \\
N01 & 550 & 694 & $\mathbf{1 1 4 7}$ & 130 & 936 & $\mathbf{1 1 2 5}$ & 80 & 626 & $\mathbf{1 1 9 7}$ \\
N02 & 178 & 318 & 504 & 238 & 592 & $\mathbf{1 6 9 1}$ & 264 & 696 & $\mathbf{1 1 6 4}$ \\
N03 & 71 & 86 & 232 & 319 & 396 & 431 & 297 & 604 & 927 \\
N04 & 173 & 192 & 221 & 413 & 502 & 674 & 550 & 763 & $\mathbf{1 0 4 2}$ \\
N05 & 250 & 344 & 455 & 1129 & 1223 & $\mathbf{1 3 1 8}$ & 625 & 654 & 824 \\
N06 & 258 & 297 & 356 & 955 & 983 & $\mathbf{1 2 1 7}$ & 336 & 496 & 576 \\
\hline
\end{tabular}



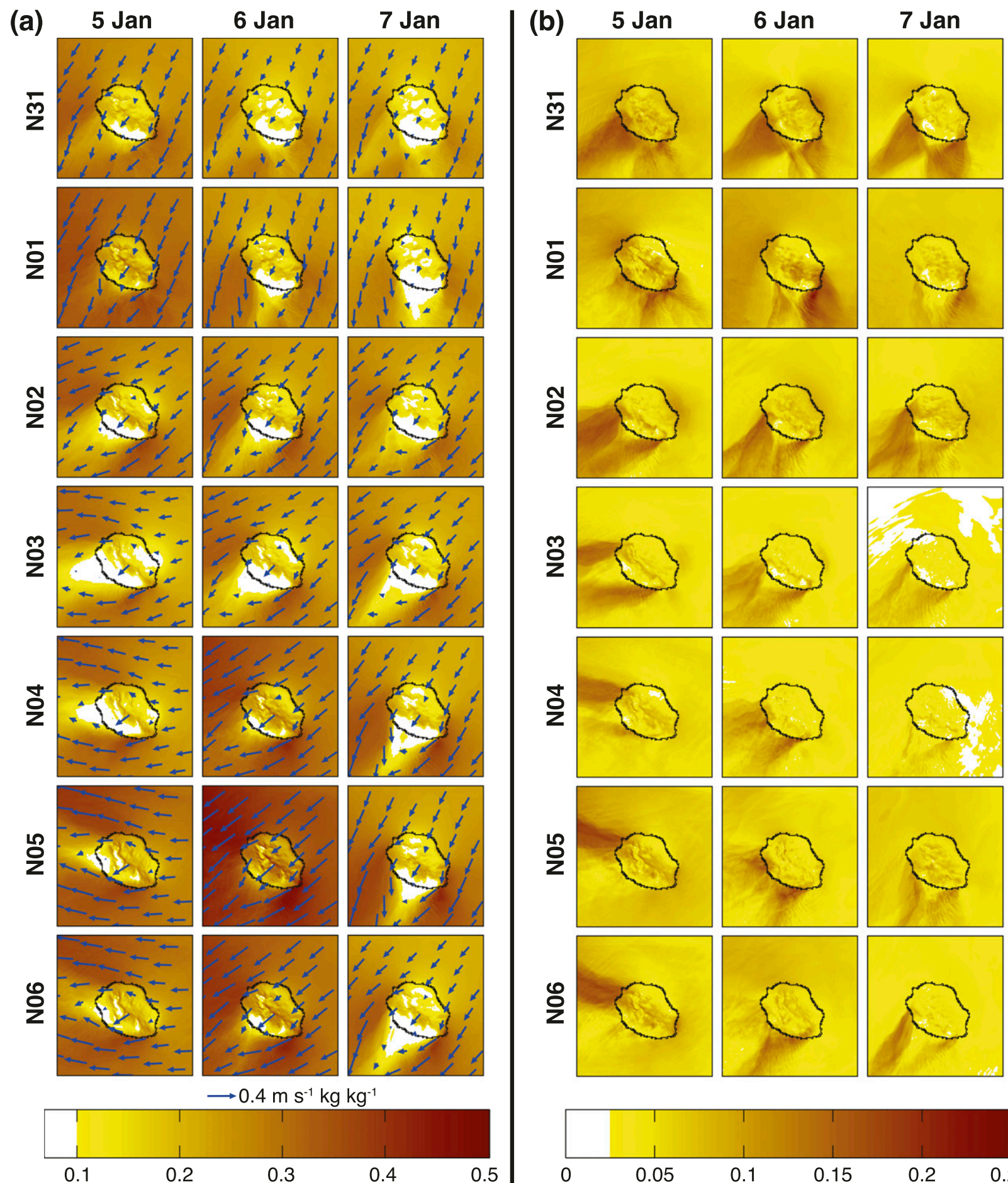

$\longrightarrow 0.4 \mathrm{~m} \mathrm{~s}^{-1} \mathrm{~kg} \mathrm{~kg}^{-1}$

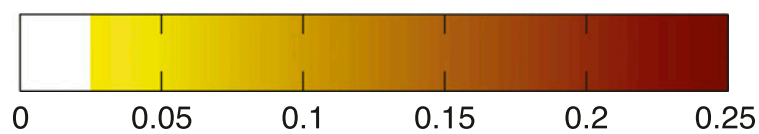

FIG. 10. (a) Ensemble mean simulation of 10-m horizontal wind $\left(\mathrm{m} \mathrm{s}^{-1}\right.$ ) for (from left to right) 5-7 Jan 2001, for (from top to bottom) the seven ensemble simulations (N31-N06), as simulated by WRF domain 4. Colors represent the modulus of the horizontal wind. Vectors show both modulus and direction; for readability, only one grid point out of 1280 is represented. (b) As in (a), but for the intermember standard deviation (m s ${ }^{-1}$ ).

Retained variables are the geographical coordinates [latitude (lat), longitude (lon), altitude (alt)] that document both horizontal and vertical gradients. The variables "slope" and "distance to the sea" were discarded because they are strongly correlated with the altitude (correlation coefficient $r=0.54$ and 0.78 , respectively): they explain little extra variance and make interpretations more difficult due to the colinearity 

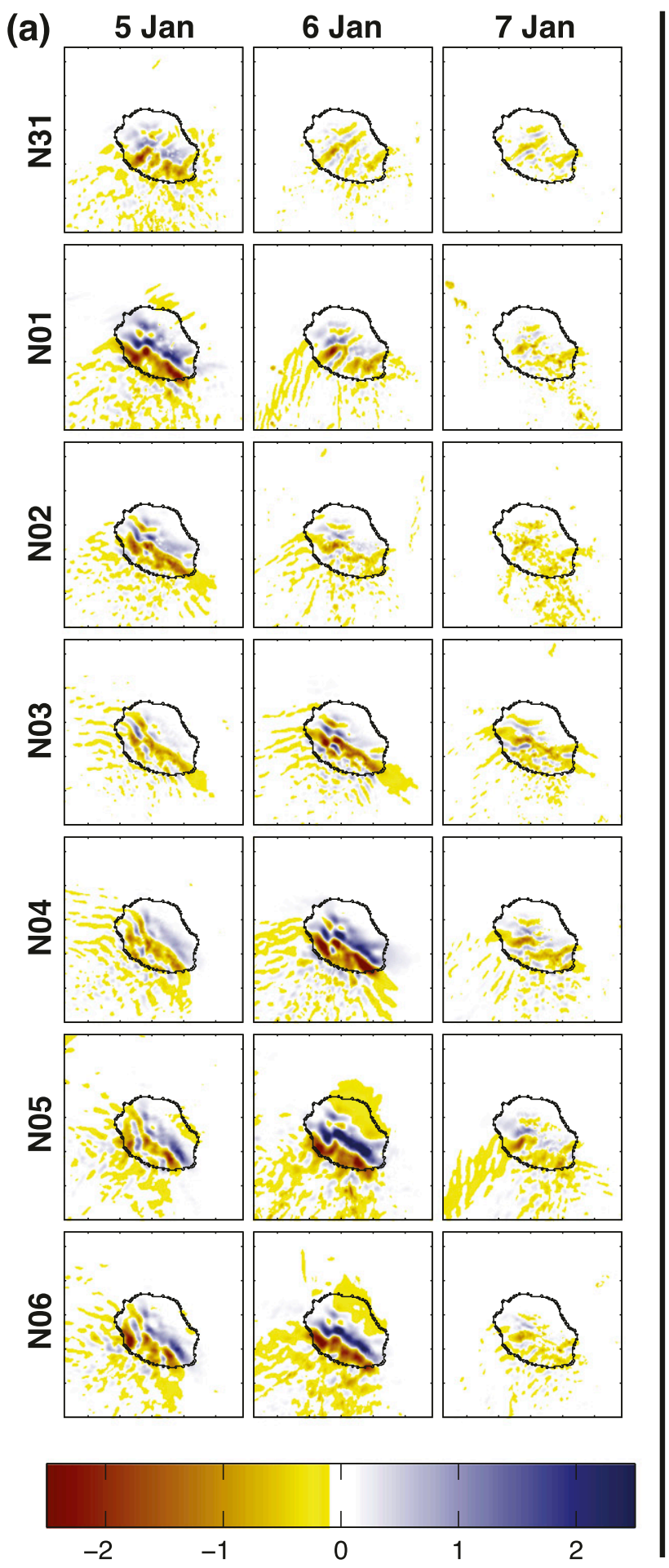

FIG. 11. As in Fig. 10, but for the vertical component of the wind at $500 \mathrm{hPa}\left(\mathrm{m} \mathrm{s}^{-1}\right)$.

between regressors. We also attempted to include a dynamical predictor corresponding to the exposure of local terrain to the wind, which can also be interpreted as the vertical component of wind due to orographic lifting
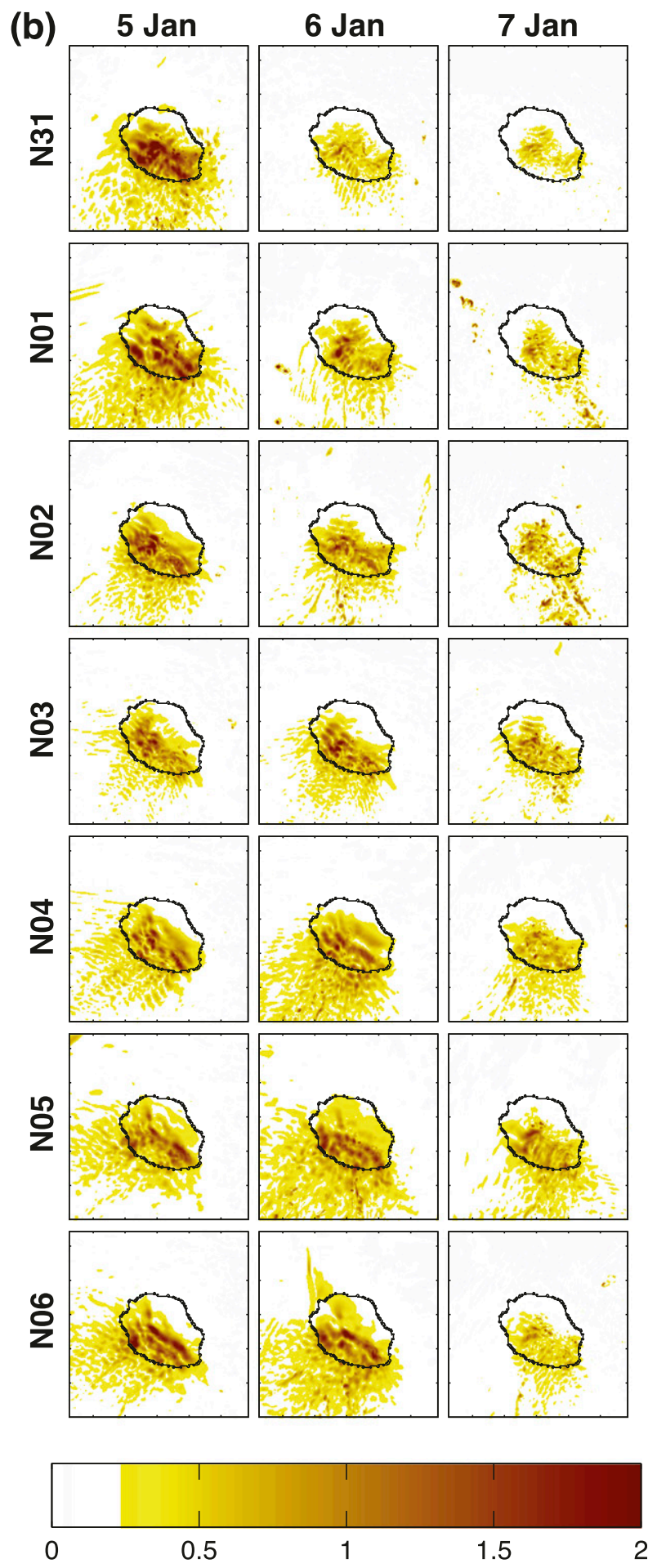

at the local scale. This was computed as the inner product of directional elevation gradients with the interpolated 700-hPa horizontal winds [M14; Kyriakidis et al. 2001, their Eq. (1)]. Surprisingly, this variable was 
TABLE 2. Orographic forcing and spatial distribution of daily rainfall over La Réunion according to rain gauge records (Obs), kriged fields (RK), and WRF ensemble simulations (N31-N06), for 5-7 Jan. DOF refers to the number of degrees of freedom of the 2D daily rainfall field; $a-d$ are the regression coefficients according to Eq. (1), and $r^{2}$ indicates the fraction of spatial variance (\%) explained by the multiple linear regression. For each WRF ensemble, the three values correspond to the (left) min, (middle) median, and (right) max value among the five members. See text for details.

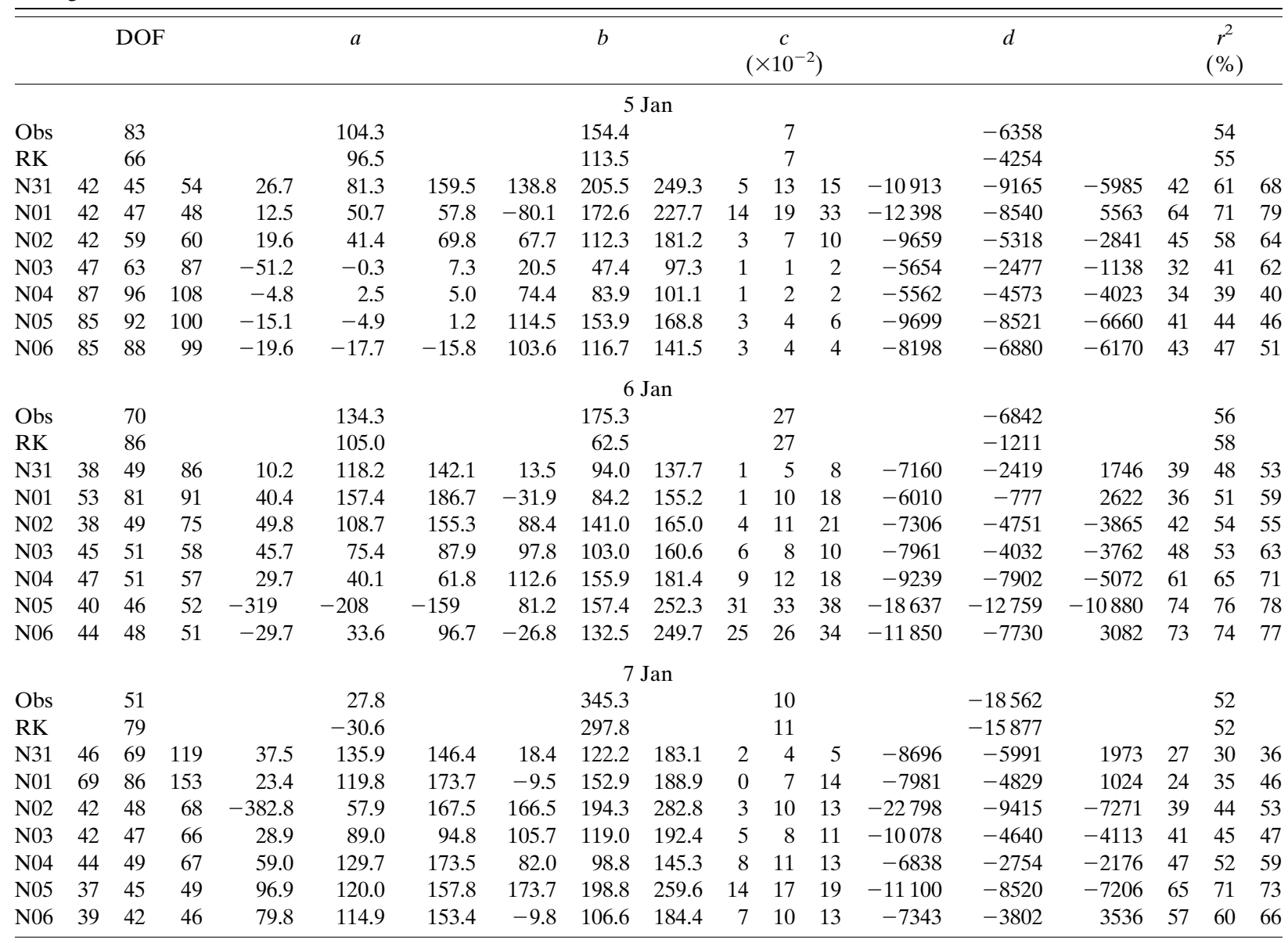

found to explain very little spatial variance of the rainfall field, either used alone in a simple regressive model (less than $7 \%$ ) or included in the multiple regression together with the other regressors (less than $+2 \%$ ). This is due to the noisy character of the directional elevation gradients, while the rainfall field is more coherent spatially. It was therefore not included in the final regressive model. In the end, the multiple linear regression is solely based on three orthogonal coordinates (lat, lon, alt) and takes the form

$$
P_{\text {est }}=a \times \text { lat }+b \times \text { lon }+c \times \text { alt }+d
$$

where $P_{\text {est }}$ is the estimated daily rainfall field, based on the regression, over the 5435 grid points (or the 86 sites of the rain gauges for the observations) over La Réunion. Table 2 presents the coefficients of the regressions applied to observed, kriged, and WRF-simulated daily rainfall amounts over La Réunion, together with the explained variance $r^{2}$ and an estimate of the spatial autocorrelation of the daily rainfall fields. The latter are obtained by calculating their effective number of degrees of freedom (DOF) using the methodology of Der Mégréditchian (1991). This highlights, for instance, that, despite the much larger number of grid points and the regular sampling of the whole island, the number of DOF is rather similar between observations, RK fields, and WRF simulations, making statistics such as the $r^{2}$ comparable from one dataset to another.

For this sequence of three days (5-7 January) during which large to extreme amounts of rainfall were observed (Fig. 2), the horizontal and vertical gradients explain between $25 \%$ and $80 \%$ of the spatial variance of rainfall. These values are restricted to $52 \%-58 \%$ according to RK fields and the network of rain gauges. Closer examination of WRF simulations reveals large and rather constant values during the simulated rainfall peak over the island (i.e., 5 January for N31 and N01, and 6 January for N05 and N06; see Fig. 5). This denotes a slightly overestimated 
orographic influence in WRF. For these days, simulated daily rainfall has indeed too strong (though rather variable from one member to another) altitudinal gradients. As can be seen in Table 2, there is a clear tendency toward overestimating coefficient $c$ during the simulated rainfall peak. There are also some difficulties in locating the largest amounts over the island (as inferred by a large spread and even possible sign errors and uncertainties from one member to another, in coefficients $a$ and $b$ ). Analysis of coefficient $d$ is of little interest: it is an adjustment variable necessary to obtain a realistic background value.

Analysis of these regressions based on surface properties suggests stronger orographic forcing/influence of the surface fields (orography and possibly land use) in WRF, or at least a stronger spatial variability partly inherited from the higher resolution and the systematic sampling of the territory. In contrast, the reliability of the RK fields is strongly determined by the density of the rain gauge network, which decreases over the regions with the steepest topography (the slopes of the Cirques and the eastern flank of La Fournaise volcano): please refer to M14 for a more exhaustive discussion. There, the interpretation of the RK fields should be made with caution. More generally, the RK fields are likely to smooth the rainfall field over La Réunion. Our results also confirm the tendency of the WRF Model to produce too marked altitudinal gradients during the rainfall peak associated with the TC. As shown by the concomitant analysis of the corresponding wind, rainfall is caused by deep atmospheric convection over the main orographic features of the island (mostly the elevated regions of the Piton des Neiges in the central part of La Réunion and La Fournaise in the southeast, where the largest amounts are recorded and simulated; Figs. 2 and 6).

In the case of TC Ando, and with a focus given on local rainfall over La Réunion, there is no direct effect of the precise location and intensity of the vortex, and the location of the convective bands surrounding the system. The main uncertainties controlling the local rainfall are the lower-level flows (and associated direction and modulus) at the periphery of the TC. Upstream of the island, the latter are forced to ascend over the relief and locally cause extreme daily amounts.

\section{Discussion and conclusions}

The island of La Réunion $\left(20^{\circ} \mathrm{S}\right)$ holds most of the world records for rainfall amounts at short time scales (from $12 \mathrm{~h}$ to 15 days) due to the effect of cyclonic activity. The island is rather small $\left(2512 \mathrm{~km}^{2}\right)$ but with a steep topography ( $>3000 \mathrm{~m} \mathrm{MSL})$ and is surrounded by a warm ocean (SST $>27^{\circ}-28^{\circ} \mathrm{C}$ during austral summer). All ingredients are gathered to cause heavy rainfall and potentially devastating effects for the environment and local populations ( $>800000$ inhabitants). Thus, the question of the impacts of TCs at finescales over the island, either due to abundant rainfall, cyclonic swell, or violent surface wind, is of primary importance.

In this paper, we used the nonhydrostatic WRF Model to simulate the rainfall amounts associated with TC Ando (31 December 2000-9 January 2001), which was associated with 24-h accumulated rainfall exceeding $1200 \mathrm{~mm}$ in the elevated parts of the island. The model setup includes four nested domains, the first of which resolving the TC's environment and trajectory, while the fourth (inner) domain documents its impacts over $\mathrm{La}$ Réunion at a 680-m horizontal resolution.

On 6 January Ando reached its closest location to the island $(215 \mathrm{~km})$ with 10 -min sustained wind peaks of $195 \mathrm{~km} \mathrm{~h}^{-1}$. WRF simulations show that local rainfall over La Réunion is due to strong lower-level moisture fluxes forced to ascend over the island due to orographic uplift. In model ensemble simulations, the key factor responsible for most uncertainties from one member to another is the intensity and direction of the atmospheric fluxes close to the surface, and in the neighborhood of the island. The latter depends on the relative location of the TC, its intensity and its structure. Thus, the aim of this work was to relate such large-scale features of the TC and its local effects over La Réunion. Focus was given on the model's biases and internal variability across scales, from the synoptic situation (characteristics of the simulated TC: trajectory, intensity, extension) to its localized impacts. In the model setup, the first one is simulated by the coarser grids, while the latter are resolved using a cloud-resolving grid and high-resolution surface boundary conditions (including both digital elevation model and land-use maps).

Results suggest that the model is capable of simulating both amounts and spatial distribution of local rainfall. This is particularly true when the model's prognostic variables are relaxed (nudged) toward the large-scale features derived from forcing ERA-Interim, leading as expected to more realistic TC trajectories. In the absence of atmospheric nudging, the model is likely to simulate too early rainfall peak timing due to biased propagations of the TC, or to miss completely the rainfall peak because the TC moves too far from the island. A realistic rainfall field over La Réunion can only be obtained with a lead time of roughly $24-48 \mathrm{~h}$ (i.e., guided simulations ending or analyses performed on 5 January, leading to correct rainfall amounts and distribution on 6 January). This is because the TC tends to propagate too far west in the absence of a relaxation term, and remains too far to cause significant rainfall amounts over 
TABLE 3. Sensitivity of rainfall amounts over La Réunion to the horizontal resolution of the model grids. For each ensemble simulation (N31-N06) and for 5-7 Jan, the average daily rainfall amount averaged over the region $20.7^{\circ}-21.5^{\circ} \mathrm{S}, 55^{\circ}-56^{\circ} \mathrm{E}$ encompassing La Réunion is indicated. For each ensemble, the three values correspond to the (left) min, (middle) median, and (right) max value among the five members. The horizontal resolution of each domain (d01-d04) and the number of grid points ( $\mathrm{gp}$ ) included in the analysis are labeled in the table.

\begin{tabular}{|c|c|c|c|c|c|c|c|c|c|c|c|c|}
\hline & $\mathrm{d} 01$ & $45 \mathrm{~km}$ & $3 \mathrm{gp})$ & d02 ( & $36 \mathrm{~km} ; 8$ & $10 \mathrm{gp})$ & d03 & $\mathrm{km} ; 34$ & $41 \mathrm{gp})$ & d04 & $\mathrm{m} ; 136$ & $64 \mathrm{gp})$ \\
\hline & & & & & & 5 Jan & & & & & & \\
\hline N31 & 16.73 & 27.99 & 33.42 & 19.28 & 33.19 & 38.33 & 17.92 & 30.50 & 35.79 & 17.95 & 30.50 & 35.78 \\
\hline N01 & 28.45 & 34.40 & 115.40 & 33.98 & 40.67 & 111.33 & 31.22 & 37.42 & 105.22 & 31.22 & 37.43 & 105.51 \\
\hline N02 & 6.20 & 12.97 & 20.14 & 7.41 & 15.52 & 24.13 & 6.83 & 14.29 & 22.18 & 6.83 & 14.30 & 22.19 \\
\hline N03 & 2.05 & 6.55 & 8.29 & 2.54 & 7.48 & 9.51 & 2.38 & 7.07 & 9.02 & 2.37 & 7.11 & 9.05 \\
\hline N04 & 4.35 & 4.62 & 6.25 & 5.15 & 5.67 & 7.59 & 4.92 & 5.29 & 7.09 & 4.93 & 5.28 & 7.09 \\
\hline N05 & 6.90 & 9.54 & 12.20 & 8.45 & 11.59 & 14.77 & 7.91 & 10.74 & 13.65 & 7.90 & 10.73 & 13.64 \\
\hline N06 & 6.89 & 8.85 & 10.07 & 8.41 & 10.67 & $\begin{array}{c}12.22 \\
6 \mathrm{Jan}\end{array}$ & 7.86 & 9.94 & 11.32 & 7.86 & 9.94 & 11.31 \\
\hline N31 & 5.29 & 14.18 & 16.28 & 6.17 & 16.93 & 17.76 & 5.87 & 15.57 & 16.92 & 5.88 & 15.58 & 17.02 \\
\hline N01 & 3.50 & 20.49 & 32.04 & 3.99 & 23.89 & 38.08 & 3.70 & 22.12 & 35.01 & 3.71 & 22.15 & 35.02 \\
\hline N02 & 7.53 & 22.05 & 39.79 & 9.03 & 26.34 & 46.81 & 8.29 & 24.20 & 43.37 & 8.29 & 24.20 & 43.38 \\
\hline N03 & 10.76 & 12.48 & 16.70 & 12.92 & 15.45 & 20.09 & 11.87 & 14.20 & 18.46 & 11.87 & 14.19 & 18.46 \\
\hline N04 & 17.40 & 22.94 & 31.17 & 20.07 & 27.24 & 37.03 & 18.46 & 25.04 & 34.08 & 18.46 & 25.04 & 34.09 \\
\hline N05 & 59.95 & 67.21 & 74.39 & 71.08 & 78.81 & 88.13 & 65.63 & 72.76 & 81.28 & 65.66 & 72.78 & 81.26 \\
\hline N06 & 45.63 & 48.66 & 72.07 & 54.01 & 56.75 & $\begin{array}{c}85.75 \\
7 \text { Jan }\end{array}$ & 49.81 & 52.23 & 79.37 & 49.82 & 52.24 & 79.33 \\
\hline N31 & 6.64 & 10.96 & 12.51 & 7.97 & 12.96 & 14.98 & 7.35 & 11.93 & 13.77 & 7.35 & 11.93 & 13.77 \\
\hline N01 & 2.87 & 16.16 & 30.40 & 2.89 & 19.19 & 33.03 & 2.72 & 17.69 & 30.96 & 2.72 & 17.70 & 31.10 \\
\hline N02 & 10.96 & 23.78 & 69.48 & 13.16 & 27.80 & 71.73 & 12.17 & 25.58 & 69.04 & 12.17 & 25.59 & 69.71 \\
\hline N03 & 9.26 & 13.30 & 25.01 & 11.11 & 15.92 & 28.51 & 10.20 & 14.63 & 26.53 & 10.20 & 14.63 & 26.61 \\
\hline N04 & 15.64 & 19.71 & 23.69 & 18.65 & 23.60 & 28.04 & 17.14 & 21.68 & 25.78 & 17.15 & 21.69 & 25.79 \\
\hline N05 & 28.24 & 33.47 & 38.31 & 32.84 & 39.55 & 44.98 & 30.20 & 36.36 & 41.33 & 30.20 & 36.37 & 41.33 \\
\hline N06 & 13.82 & 21.15 & 32.95 & 16.41 & 25.05 & 39.44 & 15.21 & 23.23 & 36.71 & 15.21 & 23.24 & 36.70 \\
\hline
\end{tabular}

the island. The main interest in the nudging, in spite of the rather low resolution of the reanalyses that act to reduce the TC's intensity, is here to constraint its track, and thus its distance to La Réunion and its propagation speed.

Although current atmospheric models show some skill in predicting the TC's evolutions at large scales, associated effects at finescales over complex terrains are more difficult to simulate. In the present case, once the $\mathrm{TC}$ is close enough to modulate lower-level moisture fluxes upstream of the island, the orographic forcing seems to be predominant over the intrinsic properties of the cyclone (i.e., a biased TC in terms of precise location, intensity, or size). This is probably because the TC did not reach the island and caused severe local impacts indirectly, mainly through orographic forcing. Thus, in such cases, even poorly simulated TC structures can induce realistic rainfall amounts and distribution over the island due to the better representation of topography in high-resolution simulations. This point, which is consistent with recent studies conducted over Taiwan by Wang (2015) and Wang et al. (2016), is particularly meaningful for operational forecasts and shows that realistic local rainfall estimates could be obtained despite the partly biased TC life cycle. Conversely, over complex terrain, reliable local estimates of severe weather events require very high-resolution grids so as to properly take into account both orographic effects and finescale processes modulated by the surface conditions. The added-value of grid refinements is illustrated and quantified in Tables 3 and 4 . At the scale of the island (Table 3), forecasted daily rainfall amounts appear independent of the grid resolution, suggesting that the benefit of using cloud-resolving domains is almost negligible. These mean values nevertheless mask a strong spatial variability that must definitely be taken into account to properly assess local TC impacts. Indeed, local maxima of daily rainfall amounts are strongly resolution dependent (Table 4). The need for highresolution domains, much more demanding computationally, thus depends on both the problematic part of the study and the need for local estimates in the case of strongly anisotropic and spatially heterogeneous variables. In this regard, forecasting extreme rainfall over La Réunion appears as one of the most challenging types of exercises.

Additional case studies are needed to assess the robustness of the conclusions raised from the study of TC Ando. In particular, the case of TCs approaching or even reaching the island could bring complementary pieces of 
TABLE 4. As in Table 3, but for the largest rainfall daily amount reached over the area.

\begin{tabular}{|c|c|c|c|c|c|c|c|c|c|c|c|c|}
\hline & \multicolumn{3}{|c|}{$\mathrm{d} 01(43.45 \mathrm{~km} ; 2 \times 3 \mathrm{gp})$} & \multicolumn{3}{|c|}{$\mathrm{d} 02(10.86 \mathrm{~km} ; 8 \times 10 \mathrm{gp})$} & \multicolumn{3}{|c|}{$\mathrm{d} 03(2.72 \mathrm{~km} ; 34 \times 41 \mathrm{gp})$} & \multicolumn{3}{|c|}{$\mathrm{d} 04(680 \mathrm{~m} ; 136 \times 164 \mathrm{gp})$} \\
\hline \multicolumn{13}{|c|}{$5 \mathrm{Jan}$} \\
\hline N31 & 39 & 68 & 79 & 196 & 312 & 358 & 332 & 625 & 814 & 435 & 876 & 1178 \\
\hline N01 & 75 & 96 & 244 & 336 & 414 & 704 & 617 & 788 & 1229 & 793 & 965 & 1353 \\
\hline N02 & 16 & 36 & 49 & 97 & 186 & 245 & 163 & 329 & 466 & 227 & 401 & 605 \\
\hline N03 & 5 & 14 & 25 & 40 & 55 & 136 & 84 & 89 & 228 & 107 & 130 & 268 \\
\hline N04 & 12 & 13 & 17 & 96 & 104 & 132 & 167 & 182 & 221 & 214 & 220 & 259 \\
\hline N05 & 21 & 26 & 34 & 167 & 214 & 295 & 257 & 357 & 453 & 301 & 397 & 526 \\
\hline N06 & 21 & 26 & 29 & 159 & 203 & $\begin{array}{r}235 \\
6\end{array}$ & 256 & 323 & 380 & 298 & 381 & 421 \\
\hline N31 & 14 & 43 & 49 & 86 & 170 & 215 & 137 & 358 & 694 & 185 & 506 & 1063 \\
\hline N01 & 15 & 64 & 107 & 56 & 225 & 365 & 120 & 717 & 894 & 167 & 1272 & 1539 \\
\hline N02 & 23 & 64 & 120 & 152 & 267 & 419 & 283 & 573 & 1040 & 355 & 776 & 1915 \\
\hline N03 & 31 & 40 & 44 & 147 & 173 & 227 & 311 & 381 & 461 & 387 & 504 & 563 \\
\hline N04 & 48 & 64 & 88 & 206 & 311 & 441 & 458 & 671 & 716 & 541 & 784 & 854 \\
\hline N05 & 162 & 178 & 204 & 738 & 802 & 875 & 1128 & 1238 & 1363 & 1262 & 1365 & 1514 \\
\hline N06 & 135 & 142 & 205 & 563 & 575 & $\begin{array}{r}783 \\
7\end{array}$ & 984 & 1106 & 1191 & 1138 & 1222 & 1354 \\
\hline N31 & 24 & 32 & 35 & 117 & 159 & 249 & 266 & 364 & 447 & 308 & 468 & 567 \\
\hline N01 & 8 & 46 & 71 & 30 & 225 & 350 & 70 & 636 & 1347 & 105 & 833 & 2192 \\
\hline N02 & 36 & 67 & 166 & 169 & 281 & 481 & 269 & 908 & 1077 & 324 & 1009 & 1670 \\
\hline N03 & 26 & 38 & 59 & 173 & 216 & 282 & 323 & 571 & 781 & 419 & 708 & 1141 \\
\hline N04 & 48 & 60 & 64 & 197 & 264 & 328 & 546 & 687 & 760 & 723 & 871 & 1094 \\
\hline N05 & 79 & 91 & 110 & 343 & 403 & 430 & 532 & 651 & 715 & 726 & 767 & 921 \\
\hline N06 & 42 & 59 & 110 & 176 & 256 & 314 & 340 & 453 & 541 & 450 & 644 & 724 \\
\hline
\end{tabular}

information. A complementary approach could also consist of refining the inner grids to hectometric scales, allowing for the resolution of large-scale atmospheric eddies [large-eddy simulations (LESs)]. The respective role of finer surface conditions and changes in the model physics allowed by the very high resolution could be addressed (for instance, by smoothing the topography in LES experiments).

The predictability of high-resolution TC effects over La Réunion is another key issue that has yet to be explored. Using newly released reforecast datasets such as NOAA's Re-Forecasting dataset version 2 (RF2; Hamill et al. 2013) instead of reanalyzed fields may help identifying the main sources of uncertainties, from largescale prediction errors to local-scale biases in the TC impacts and effects associated with wind and heavy rainfall, with the ultimate goal being to regionalize and predict TC effects over complex terrain to help local populations anticipate and adapt to such risks.

Acknowledgments. The authors thank the three anonymous reviewers for their constructive comments, which significantly improved the manuscript. This work is a contribution to the CNRS/INSU LEFE/IMAGO "Koudvan" project. The authors thank the "Koudvan" meeting participants for the helpful discussions, which assisted in improving the results. WRF data were provided by the University Corporation for Atmospheric Research website (http://www2.mmm.ucar.edu/wrf/users/download/). ERA-Interim data were provided by the ECMWF Meteorological Archival and Retrieval System (MARS). Calculations were performed using HPC resources from DSI-CCUB, Université de Bourgogne.

\section{REFERENCES}

Alexandru, A., R. De Elia, and R. Laprise, 2007: Internal variability in regional climate downscaling at the seasonal scale. Mon. Wea. Rev., 135, 3221-3238, doi:10.1175/MWR3456.1.

Barcelo, A., and J. Coudray, 1996: Nouvelle carte des isohyètes annuelles et des maxima pluviométriques sur le massif du Piton de la Fournaise (île de la Réunion). Rev. Sci. Eau, 9, 457484, doi:10.7202/705262ar.

_ R. Robert, and J. Coudray, 1997: A major rainfall event: The 27 February-5 March 1993 rains on the southeastern slope of Piton de la Fournaise Massif (Reunion Island, southwest Indian Ocean). Mon. Wea. Rev., 125, 3341-3346, doi:10.1175/ 1520-0493(1997)125<3341:AMRETF>2.0.CO;2.

Cangialosi, J. P., and J. L. Franklin, 2012: 2011 National Hurricane Center forecast verification report. NOAA, $76 \mathrm{pp}$.

Chen, F., and J. Dudhia, 2001a: Coupling an Advanced Land SurfaceHydrology Model with the Penn State-NCAR MM5 Modeling System. Part I: Model Implementation and sensitivity. Mon. Wea. Rev., 129, 569-585, doi:10.1175/1520-0493(2001)129<0569: CAALSH $>2.0 . \mathrm{CO} ; 2$.

$\longrightarrow$, and - , 2001b: Coupling an Advanced Land SurfaceHydrology Model with the Penn State-NCAR MM5 Modeling System. Part II: Preliminary model validation. Mon. Wea. Rev., 129, 587-604, doi:10.1175/1520-0493(2001)129<0587: CAALSH $>2.0 . \mathrm{CO} ; 2$. 
Crétat, J., C. Macron, B. Pohl, and Y. Richard, 2011: Quantifying internal variability in a regional climate model: A case study for Southern Africa. Climate Dyn., 37, 1335-1356, doi:10.1007/ s00382-011-1021-5.

Daloz, A.-S., and Coauthors, 2015: Cluster analysis of downscaled and explicitly simulated North Atlantic tropical cyclone tracks. J. Climate, 28, 1333-1361, doi:10.1175/JCLI-D-13-00646.1.

Dee, D. P., and Coauthors, 2011: The ERA-Interim reanalysis: Configuration and performance of the data assimilation system. Quart. J. Roy. Meteor. Soc., 137, 553-597, doi:10.1002/ qj.828.

DeMaria, M., C. R. Sampson, J. A. Knaff, and K. D. Musgrave, 2014: Is tropical cyclone intensity guidance improving? Bull. Amer. Meteor. Soc., 95, 387-398, doi:10.1175/BAMS-D-12-00240.1.

Der Mégréditchian, G., 1991: Le Traitement Statistique des Données Multi-Dimensionnelles: Application à la Météorologie. Vol. 1, Cours et Manuels 8, Météo-France, 287 pp.

Dudhia, J., 1989: Numerical study of convection observed during the Winter Monsoon Experiment using a mesoscale twodimensional model. J. Atmos. Sci., 46, 3077-3107, doi:10.1175/ 1520-0469(1989)046<3077:NSOCOD > 2.0.CO;2.

Falvey, R., 2012: Summary of the 2011 western Pacific/Indian Ocean tropical cyclone season. Proc. 66th Interdepartmental Hurricane Conf., Charleston, SC, OFCM. [Available online at http://www.ofcm.gov/ihc12/Presentations/01b-Session/05-JTWC_ 2012_IHC_Final.pdf.]

Giorgi, F., and X. Bi, 2000: A study of internal variability of a regional climate model. J. Geophys. Res., 105, 29 503-29 521, doi:10.1029/ 2000JD900269.

Hamill, T. M., G. T. Bates, J. S. Whitaker, D. R. Murray, M. Fiorino, T. J. Galarneau Jr., Y. Zhu, and W. Lapenta, 2013: NOAA's second-generation global medium-range ensemble reforecast data set. Bull. Amer. Meteor. Soc., 94, 1553-1565, doi:10.1175/BAMS-D-12-00014.1.

Hong, S.-Y., and J.-O. J. Lim, 2006: The WRF Single-Moment 6-Class Microphysics Scheme (WSM6). J. Korean Meteor. Soc., 42, 129-151.

_- Y. Noh, and J. Dudhia, 2006: A new vertical diffusion package with an explicit treatment of entrainment processes. Mon. Wea. Rev., 134, 2318-2341, doi:10.1175/MWR3199.1.

Kain, J. S., 2004: The Kain-Fritsch convective parameterization: An update. J. Appl. Meteor., 43, 170-181, doi:10.1175/ 1520-0450(2004)043<0170:TKCPAU > 2.0.CO;2.

Knapp, K. R., M. C. Kruk, D. H. Levinson, H. J. Diamond, and C. J. Neumann, 2010: The International Best Track Archive for Climate Stewardship (IBTrACS). Bull. Amer. Meteor. Soc. 91, 363-376, doi:10.1175/2009BAMS2755.1.

Kyriakidis, P. C., J. Kim, and N. L. Miller, 2001: Geostatistical mapping of precipitation from rain gauge data using atmospheric and terrain characteristics. J. Appl. Meteor., 40, 1855-1877, doi:10.1175/1520-0450(2001)040<1855:GMOPFR > 2.0.CO;2.

Liu, B., and L. Xie, 2012: A scale-selective data assimilation approach to improving tropical cyclone track and intensity forecasts in a limited-area model: A case study of hurricane Felix (2007). Wea. Forecasting, 27, 124-140, doi:10.1175/ WAF-D-10-05033.1.
Ma, L.-M., and Z.-M. Tan, 2009: Improving the behavior of the cumulus parameterization for tropical cyclone prediction: Convection trigger. Atmos. Res., 92, 190-211, doi:10.1016/ j.atmosres.2008.09.022.

Mlawer, E. J., S. J. Taubman, P. D. Brown, and M. J. Iacono, 1997: Radiative transfer for inhomogeneous atmospheres: RRTM, a validated correlated-k model for the longwave. J. Geophys. Res., 102, 16 663-16 682, doi:10.1029/97JD00237.

Mohapatra, M., B. K. Bandyopadhyay, and D. P. Nayak, 2013: Evaluation of operational tropical cyclone intensity forecasts over north Indian Ocean issued by India Meteorological Department. Nat. Hazards, 68, 433-451, doi:10.1007/s11069-013-0624-z.

Morel, B., B. Pohl, Y. Richard, B. Bois, and M. Bessafi, 2014: Regionalizing rainfall at very high resolution over La Réunion island using a regional climate model. Mon. Wea. Rev., 142, 2665-2686, doi:10.1175/MWR-D-14-00009.1.

Pohl, B., and J. Crétat, 2014: On the use of nudging techniques for regional climate modeling: Application for tropical convection. Climate Dyn., 43, 1693-1714, doi:10.1007/s00382-013-1994-3.

Separovic, L., R. de Elía, and R. Laprise, 2008: Reproducible and irreproducible components in ensemble simulations with a regional climate model. Mon. Wea. Rev., 136, 4942-4961, doi:10.1175/2008MWR2393.1.

Simmons, A. J., S. M. Uppala, D. P. Dee, and S. Kobayashi, 2007: ERA-Interim: New ECMWF reanalysis products from 1989 onwards. ECMWF Newsletter, No. 110, ECMWF, Reading, United Kingdom, 25-35.

Skamarock, W. C., and J. B. Klemp, 2008: A time-split nonhydrostatic atmospheric model for weather research and forecasting applications. J. Comput. Phys., 227, 3465-3485, doi:10.1016/j.jcp.2007.01.037.

, and Coauthors, 2008: A description of the Advanced Research WRF version 3. NCAR Tech. Note NCAR/TN-475+STR, 113 pp., doi:10.5065/D68S4MVH.

Walsh, K., 1997: Objective detection of tropical cyclones in highresolution analyses. Mon. Wea. Rev., 125, 1767-1779, doi:10.1175/ 1520-0493(1997)125<1767:ODOTCI > 2.0.CO;2.

Wang, C.-C., 2015: The more rain, the better the model performsThe dependency of quantitative precipitation forecast skill on rainfall amount for typhoons in Taiwan. Mon. Wea. Rev., 143, 1723-1748, doi:10.1175/MWR-D-14-00137.1.

- S.-Y. Huang, S.-H. Chen, C.-S. Chang, and K. Tsuboki, 2016: Cloud-resolving typhoon rainfall ensemble forecasts for Taiwan with large domain and extended range through timelagged approach. Wea. Forecasting, 31, 151-172, doi:10.1175/ WAF-D-15-0045.1.

WMO, 2011: Seventh International Workshop on Tropical Cyclones (IWTC-VII). WMO Final Rep. WWRP 2011-1, WMO/ TD-1561, 79 pp. [Available online at https://www.wmo.int/ pages/prog/arep/wwrp/new/documents/final_WWRP_2011_ 1_TD_No_1561.pdf.]

, 2014: Recommendations. Eighth Int. Workshop on Tropical Cyclones (IWTC-VIII), Jeju, South Korea, WWRP and TCP, $4 \mathrm{pp}$. [Available online at http://www.wmo.int/pages/prog/ $\operatorname{arep} / \mathrm{wwrp} / \mathrm{tmr} /$ documents/ListofRecommendations.pdf.] 